ISSN (print) 0867-2008 / ISSN (online) 2391-7512

DOI: http://dx.doi.org/10.12775/OM.2021.008

MADis MAASING*

Ajaloo ja arheoloogia instituut

Tartu Ülikool

Ülikooli 18

E-50090 Tartu

Estonia

madis.maasing@ut.ee

\title{
DIE REICHSTAGSTEILNAHME DES LIVLÄNDISCHEN DEUTSCHORDENSZWEIGES UND SEINE BEZIEHUNGEN MIT DEM DEUTSCHEN ZWEIG (CA. 1520-1560)*
}

\section{KEYWORDS}

history; the Early Modern times; military orders; the Teutonic Order; communication; Holy Roman Empire; Livonia; Imperial Diets

Abstract

The participation of the Livonian branch of the Teutonic Order at the Imperial Diets and its relations with the German branch (from the I s2os to the IS5os)

This article discusses the relations of Livonian branch of the Teutonic Order with the German branch from the secularization of Prussia ( 1525 ) to the beginning of the Livonian War (I558), and concentrates on the topics that were connected with the participation of the Order at the Imperial Diet of the Holy Roman Empire. Before the aforementioned period, the branches had very few direct connections, and relations of the Livonian branch with the Empire were usually mediated by the Grand Master of the Order. After I 525, the German Master largely took over the role of a mediator, as he became the acting head of the Order and had close relations with the central Imperial institutions. The latter became increasingly important for the Livonian Master, who became an Imperial prince most probably on the 24 th of December I 526 . This enabled him to participate in the Imperial Diets. At the Diets, the branches represented their interests usually separately. This was partially caused by the fact that these diverged quite strongly: while the German branch aspired for the recuperation of Prussia, tried to protect the Order's possessions from increasing intrusions of German princes, and paid the

* ORCID: http://orcid.org/0000-0003-4636-8 196

** Das Verfassen dieses Aufsatzes wurde durch die Eesti Teadusagentuur (Estländische Wissenschaftsagentur, Projekt Nr. PRG 3 I 8) gefördert. 
Turkish taxes to obtain support from the Emperor; the Livonian branch wanted to obtain support against the Russian threat and rivals inside Livonia, while also trying to avoid paying Imperial taxes. Additionally, the Duke of Prussia was the neighbour of Livonia with whom the Livonian branch usually tried to maintain normal relations. Nevertheless, the branches communicated quite actively during the Diets and supported each other, at least in a rhetorical capacity. Additionally, Livonian envoys normally went firstly to the German Master for consultations and headed to the Diets only thereafter. Thus, the communication was quite vivid, but did not leave many marks to the official documentation, as especially the Livonian branch preferred to represent itself as a separate and independent member of the Empire in front of the Imperial Estates.

\section{EINLEITUNG}

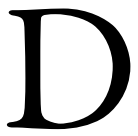
ie ersten Jahrzehnte des Reformationszeitalters waren eine der schwersten Krisenperioden für den Deutschen Orden. Preußens Säkularisation, Verluste durch die Konflikte wie der Bauernkrieg und wachsende Ambitionen der mächtigen Nachbarn zwangen die Ordenszweige in Livland und Deutschland dazu, Unterstützung beim Kaiser und bei den zentralen Strukturen des Heiligen Römischen Reichs zu suchen. ${ }^{1}$ Dabei befand sich der königsnahe deutsche Ordenszweig in einer wesentlich günstigeren Position, weil er schon jahrhundertelang enge Beziehungen zum kaiserlichen bzw. königlichen Hof gepflegt hatte und sowohl an den Reichsgeschäften als auch an den zentralen Reichsversammlungen beteiligt war. ${ }^{2}$ Die Reichszugehörigkeit des reichsfernen livländischen Zweiges war dagegen umstritten, was zum Teil daran lag, dass man mit dem Reich meistens nicht direkt, sondern über den Hochmeister in Preußen oder, viel seltener, über den deutschen Zweig kommuniziert hatte. ${ }^{3}$

I Die Ritterorden in Umbruchs- und Krisenzeiten, hrsg. v. Roman Czaja und Jürgen Sarnowsky, Ordines Militares. Colloquia Torunensia Historica XVI (Toruń: Wydawnictwo Naukowe Uniwersytetu Mikołaja Kopernika, 20 I I); Axel Herrmann, Der Deutsche Orden unter Walter von Cronberg (I525-I543). Zur Politik und Struktur der "teutschen Adels Spitale" im Reformationszeitalter, Quellen und Studien zur Geschichte des Deutschen Ordens 35 (Bonn-Bad Godesberg: Verlag Wissenschaftliches Archiv, 1974); The Military Orders and the Reformation: Choices, State Building, and the Weight of Tradition, hrsg. v. Johannes A. Mol, Klaus Militzer, und Helen J. Nicholson, Bijdragen Tot de Geschiedenis van de Ridderlijke Duitsche Orde, Balije van Utrecht 3 (Hilversum-Utrecht: Verloren, 2006).

2 Hanns H. Hofmann, Der Staat des Deutschmeisters. Studien zu einer Geschichte des Deutschen Ordens im Heiligen Römischen Reich Deutscher Nation (München: Kommission für Bayerischen Landesgeschichte, I 964); Hartmut Boockmann, "Die Vertretung des Deutschen Ordens auf den spätmittelalterlichen Reichstagen," in Nord und Süd in der deutschen Geschichte des Mittelalters, hrsg. v. Werner Paravicini, Kieler Historische Studien 34 (Sigmaringen: Thorbecke, 1990), 97-108.

3 Vgl. Mihkel Mäesalu, Liivimaa ja Püha Rooma keisririik I19g-1486, Dissertationes Historiae Universitatis Tartuensis 42 (Tartu: Tartu Ülikool, 2017), I00-I I 2, I 35-I 47, I62-I66; 
Wie beeinflusste die Säkularisation des Ordenszentrums in Preußen die Beziehungen des livländischen Zweiges mit dem deutschen? Es besteht kein Zweifel, dass sich seit den I $520 e r$ Jahren Livlands Verbindungen mit dem Reich deutlich intensivierten, ${ }^{4}$ aber bedeutete das auch engere und bessere Verhältnisse zwischen dem livländischen und dem deutschen Zweig? In welchem Ausmaß konnte der Deutschmeister als das neue provisorische Ordenshaupt die frühere Vermittlerrolle des Hochmeisters für Livland übernehmen? Hatten die Zweige überhaupt gemeinsame politische Ziele? Oder gab es vielleicht mehr Konkurrenz als Zusammenarbeit?

Die Beziehungen zwischen den Ordenszweigen nach I 525 hat die Forschung bisher eher selten behandelt. Üblicherweise hat man die Lage des deutschen oder livländischen Zweiges nur mit der Ordenszentrale in Preußen aber nicht miteinander verglichen.' Obwohl sich deutschbaltische Forscher schon seit Mit-

Elke Wimmer, "Livland - ein Problem der habsburgisch-russischen Beziehungen in der Zeit Maximilians I.?," in Deutschland - Livland - Russland: ihre Beziehungen vom I5. bis zum I7. Jahrbundert. Beiträge aus dem Historischen Seminar der Universität Hamburg Deutschland, hrsg. v. Norbert Angermann (Lüneburg: Nordostdeutsches Kulturwerk, I 988), 53- I I 0.

4 Valda Kḷava, "Livonija Svētajā Romas impērijā: problēmas izpēte un attiecību piemērs no i 6. gadsimta vidus," Latvijas Vèstures Institūta Žurnāls I (2014): I 26- I 55 ; Bernhard Demel, "Zur Reichspolitik des livländischen Ordenszweiges in den Jahren I 52 I bis I 56 I I 562 ," Ordines Militares Colloquia Torunensia Historica. Yearbook for the Study of the Military Orders 20 (2016): 145-1 72; Madis Maasing, "Livland und die Reichstage ( $520-1555$ )," in Livland - eine Region am Ende der Welt? Forschungen zum Verhältnis zwischen Zentrum und Peripherie im späten Mittelalter / Livonia - a Region at the End of the World? Studies on the Relations between Centre and Periphery in the Later Middle Ages, hrsg. v. Anti Selart und Matthias Thumser, Quellen und Studien zur baltischen Geschichte 27 (Köln-Weimar-Wien: Böhlau, 20 17), 283-3 I 2.

5 Klaus Militzer, "Unterschiede in der Herrschaftsauffassung und Herrschaft und Verwaltung in den Zweigen des Deutschen Ordens," in Herrschaft, Netzwerke, Brüder des Deutschen Ordens in Mittelalter und Neuzeit. Vorträge der Tagung der Internationalen Historischen Kommission zur Erforschung des Deutschen Ordens in Marburg 20I0, hrsg. v. Klaus Militzer, Quellen und Studien zur Geschichte des Deutschen Ordens 72 (Weimar: VDG, 20 I 2), I-23. Um die Beziehungen zwischen deutschen und livländischen Zweigen erschöpfend bewerten zu können, müßte man umfangreiche Archivarbeiten, besonders in Deutschordens-Zentralarchiv in Wien und im Schwedischen Reichsarchiv in Stockholm, durchführen. Vgl. Johannes Götz, "Das Archiv des livländischen Deuschordenszweiges. Eine archivgeschichtliche Untersuchung," in Die Kirche im mittelalterlichen Livland, hrsg. v. Radosław Biskup, Johannes Götz, und Andrzej Radzimiński, Ecclesia Clerusque Temporibus Medii Aevii 5 (Toruń: Wydawnictwo Naukowe Uniwersytetu Mikołaja Kopernika, 2019), 9-77; Juhan Kreem, "The Archives of the Teutonic Order in Livonia: Past and Present," in Entre Deus e o Rei. O Mundo Das Ordens Militares, hrsg. v. Isabel C. Ferreira Fernandes, Ordens militares 8 (Palmela: Município de Palmela. Gabinete de Estudos sobre a Ordem de Santiago, 20 1 8), 57-65; Nordosteuropa und der Deutsche Orden: Kurzregesten, Bd. I, bis I 56 , hrsg. v. Klemens Wieser, Quellen und Studien zur Geschichte des Deutschen Ordens 17 (Bad Godesberg-Bonn: Wissenschaftliches Archiv, 1969). 
te des 19. Jahrhunderts mit einigen Quellen, die Kommunikation zwischen der Ordenszweige enthielten, näher beschäftigt hatten, ${ }^{6}$ hat nur der Streit um die Hochmeisterstelle nach i 525 spezielle Aufmerksamkeit gefunden, wobei besonders frühere Autoren die Verhältnisse der Ordenszweige sehr antagonistisch darstellten. ${ }^{7}$ Spätere Forscher sind jedoch der Meinung, dass beide Zweige zu Kompromissen bereit gewesen seien, da die Erhaltung des Ordens und die Unterstützung durch das Reich für jeden Zweig wahrscheinlich wichtiger gewesen sei als die Hochmeisterwürde. ${ }^{8}$ Zusätzlich zu diesem Konflikt konzentriert man sich auf einige Beispiele der Zusammenarbeit: Johannes Götz zeigt, dass der Deutschmeister als Administrator des Hochmeistertums für den livländischen Meister eine doppelte Schlüsselrolle gespielt habe, weil er den Landmeister bzw. dessen Koadjutor bestätigt und die Übertragung der Reichsregalien (d.h., die Bestätigung des Meisters beim Kaiser bzw. römischen König) an Livland gefördert habe. ${ }^{9} \mathrm{Zu}$ dem betont Bernhard Demel, dass der deutsche Zweig den livländischen auch bei Reichsabgaben und anderen Problemen im Reich unterstützt habe. ${ }^{10}$ Allerdings kommt Axel Herrmann, der die Beziehungen der Ordenszweige während der Amtszeit des Deutschmeisters Walters von Cronberg (1 526-1 543) einer kurzen

6 "Auctarium II. Indicis Corporis Historico-Diplomatici et Epistolaris Livoniae, Esthoniae, Curoniae," hrsg. v. Karl Eduard Napiersky, Mittheilungen aus dem Gebiete der Geschichte Liv-, Ehst-und Kurland's 2 ( I 842): 485-544; Ernst Bonnell, "Das freundschaftliche Verhältniss zwischen dem Deutschmeister zu Mergentheim und den livländischen Ordensobern zur Zeit der Reformation," Mittheilungen aus dem Gebiete der Geschichte Liv-, Ehst-und Kurland's 9 ( I 860): 7I-8I.

7 Leonid Arbusow, jun., Wolter von Plettenberg und der Untergang des Deutschen Ordens in Preußen. Eine Studie aus der Reformationszeit Livlands, Schriften des Vereins für Reformationgeschichte 36/2 (Leipzig-Halle: Karras, 1919); Helene Dopkewitsch, "Die Hochmeisterfrage und das Livlandproblem nach der Umwandlung des Ordenslandes Preußen in ein weltliches Herzogtum durch den Krakauer Vertrag von April I 525," Zeitschrift für Ostforschung 16, H. 2 (1967): $201-55$.

8 Herrmann, Der Deutsche Orden, 38-72; Udo Arnold, "Livland als Glied des Deutschen Ordens in der Epoche Wolters von Plettenberg," in Wolter von Plettenberg: Der Größte Ordensmeister Livlands, hrsg. v. Norbert Angermann (Lüneburg: Verlag Nordostdeutsches Kulturwerk, 1985), 35-40; ders., "Hochmeisterverlust, Bauernunruhen und Reformation - Krisenbewältigung unter den Deutschmeistern Dietrich von Cleen und Walter von Cronberg," in Die Ritterorden in Umbruchs- und Krisenzeiten, hrsg. v. Czaja und Sarnowsky, 24 I-257.

9 Johannes Götz, "Die Wahl des livländischen Meisters: Ein Indikator für das Verhältnis zwischen Zentrum und Provinz im Deutschen Orden," Forschungen zur baltischen Geschichte 14 (2019): 55-69.

10 Demel, "Zur Reichspolitik;" ders., "Die Rekuperationsbemühungen des Deutschen Ordens um Livland von I 558/62 bis zum Ende des I 8. Jahrhunderts," in ders., Der Deutsche Orden im Spiegel seiner Besitzungen und Beziehungen in Europa, Europäische Hochschulschriften. Reihe 3, Geschichte und ihre Hilfswissenschaften 96 I (Frankfurt/Main: Lang, 2004), I93-2 I I. 
Untersuchung unterzieht, zu dem Schluss, dass die gegenseitigen Verhältnisse im Allgemeinen eher kühl und willkürlich gewesen seien. ${ }^{11}$

Dieser Aufsatz konzentriert sich vor allem auf die Verhandlungen des livländischen Zweiges auf den Reichstagen des Heiligen Römischen Reiches. Diese wurden seit Ende des I 5. Jahrhunderts die wichtigsten Diskussions- und Entscheidungsforen des Reiches und wurden von Ordensgesandten häufig besucht, wenn dort mehrere für den Orden bedeutende Fragen diskutiert wurden. ${ }^{12}$ Vor allem sollen hier die Reichstage in der Zeit von ungefähr i 520 bis I 560 behandelt werden, an denen sowohl der livländische als auch der deutsche Ordenszweig als Reichsstände beteiligt waren. ${ }^{13}$ Zusätzlich soll ein kurzer Überblick über die Unterschiede und Gemeinsamkeiten der Leitung der beiden Zweige gegeben werden, da diese ihre Kommunikation untereinander erheblich beeinflussen konnten, sowie über ihre Beziehungen vor der Säkularisation Preußens. Auch wird die Frage der Reichsstandschaft kurz betrachtet, weil sie der Faktor war, der die Teilnahme an den frühneuzeitlichen Reichstagen ermöglichte. Hierbei wird näher betrachtet, wie der livländische Meister seine Reichsfürstenwürde erhielt, weil dieser Prozess etwa ein Vierteljahrhundert lang dauerte und in voller Länge noch nicht behandelt worden ist. Außerdem ist das Datum der eigentlichen Regalienverleihung umstritten. ${ }^{14}$ Vor allem wird man sich hier auf die Beziehungen und Aktivitäten der Leitung der Ordenszweige konzentrieren, da es zumeist die Meister und nicht die einzelne Ordensballeien und -gebiete waren, deren Fragen auf den Reichstagen auftauchten.

\section{Lage und Kommunikation der Ordenszweige}

Der offensichtlichste Unterschied zwischen dem deutschen und livländischen Zweig war die geographische Lage der Herrschaftsbereiche. Während der Orden der stärkste Landesherr in Livland war, war der deutsche Zweig von lokalen Territorialmächten abhängig, denn seine Besitzungen lagen über Deutschland

I Herrmann, Der Deutsche Orden, 2 I 6-2 I 9.

${ }_{12}$ Vgl. Der Reichstag I486-I613: Kommunikation - Wabrnehmung - Öffentlichkeiten, hrsg. v. Maximilian Lanzinner und Arno Strohmeyer, Schriftenreihe der Historischen Kommission bei der Bayerischen Akademie der Wissenschaften 73 (Göttingen: Vandenhoeck \& Ruprecht, 2006).

13 Die Reichstagsmaterialien für diese Periode sind in den Deutschen Reichstagsakten größtenteils publiziert, bloß die Bände für die Reichstage von Augsburg ( 1530 ) und Nürnberg ( I 543) sind noch nicht erschienen. Auf das mit dem Livländischen Krieg ( 55 8- I 583 ) direkt verbundene reichhaltige Material wird hier nicht näher eingegangen.

${ }_{14}$ Vgl. Demel, "Die Rekuperationsbemühungen,” I 95-196; ders., "Zur Reichspolitik." 
verstreut. $^{15}$ Auch verwaltete der Deutschmeister nicht alle Ordensgebiete in Deutschland: Während vier Balleien - Koblenz, Elsass-Burgund, Österreich und Bozen (Etsch und Gebirge) - hochmeisterliche Kammergebiete waren, standen die Kommende Bremen und das Ordenshaus in Lübeck unter dem livländischen Meister. ${ }^{16}$ Außerdem hatte die Ballei Westfalen manchmal engere Beziehungen zu Livland als zum Deutschmeister. ${ }^{17}$ Andererseits bewahrten die Ordensbrüder sowohl in Deutschland als auch in Livland im Gegensatz zu Preußen ihre Mitspracherechte in der Verwaltung, weil der unmittelbare Wirkungsbereich des Meisters in beiden Zweigen auf seine Kammergebiete begrenzt war und manche Ordensbeamte ihre Gebiete eher als persönliche Güter verwalteten. ${ }^{18}$ Gemeinsam war beiden Zweigen, dass die Ritterbrüder zumeist niederadliger Herkunft waren. Auch ihre Anzahl war im I6. Jahrhundert in beiden Zweigen ähnlich, nämlich ungefähr $100 .{ }^{19}$

is Vgl. Bernhart Jähnig, Verfassung und Verwaltung des Deutschen Ordens und seiner Herrschaft in Livland, Schriften der Baltischen Historischen Kommission i 6 (Berlin: Lit, 20 I I); Rudolf Ten Haaf, Deutschordensstaat und Deutschordensballeien. Untersuchungen über Leistung und Sonderung der Deutschordensprovinzen in Deutschland vom I3. bis zum I6. Jahrhundert, Göttinger Bausteine zur Geschichtswissenschaft 5 (Göttingen: Musterschmidt, I954, 2. Auflage); Klaus Militzer, Die Entstehung der Deutschordensballeien im Deutschen Reich, Quellen und Studien zur Geschichte des Deutschen Ordens 16 (Marburg: Elwert, I98 I, 2. Auflage).

16 Klaus Militzer, "Bozen, Koblenz, Österreich und Elsass. Die Entstehung der hochmeisterlichen Kammerballeien des Deutschen Ordens," in ders., Zentrale und Region: gesammelte Beiträge zur Geschichte des Deutschen Ordens in Preußen, Livland und im Deutschen Reich aus den Jahren 1968 bis 2008, Quellen und Studien zur Geschichte des Deutschen Ordens 75 (Weimar: VDG, 201 5), 26-44; Holger S. Brünjes, Die Deutschordenskomturei in Bremen. Ein Beitrag zur Geschichte des Ordens in Livland, Quellen und Studien zur Geschichte des Deutschen Ordens 53 (Marburg: Elwert, 1997).

17 Hans J. Dorn, Die Deutschordensballei Westfalen von der Reformation bis zu ihrer Auflösung im Jahre 1809, Quellen und Studien zur Geschichte des Deutschen Ordens 26 (Marburg: Elwert, I 978), I I 5-I I 6, I 22, I 33, I 36, I 69, I 77-80; Herrmann, Der Deutsche Orden, 202-203.

18 Vgl. Herrmann, Der Deutsche Orden, I33-205, 220-243; Klaus Neitmann, "Rat und Ratsgebietiger Wolters von Plettenberg. Beobachtungen zum Regierungs- und Verwaltungsstil des Ordensmeisters," in Wolter von Plettenberg und das mittelalterliche Livland, hrsg. v. Norbert Angermann und Ilgvars Misāns (Lüneburg: Verlag Nordostdeutsches Kulturwerk, 200I), 85-I I I; Juhan Kreem, "Der Gehorsam der Gebietiger gegenüber dem livländischen Meister im I6. Jahrhundert," in Die Ritterorden als Träger der Herrschaft: Territorien, Grundbesitz und Kirche, hrsg. v. Jürgen Sarnowsky und Roman Czaja, Ordines Militares. Colloquia Torunensia Historica XIV (Toruń: Wydawnictwo Naukowe Uniwersytetu Mikołaja Kopernika, 2007), I I 5-I 26; ders., "Der Deutsche Orden in Livland im I6. Jahrhundert: Einige Betrachtungen zur Entwicklung seines Personalbestandes," Jahrbuch für die Geschichte Mittel- und Ostdeutschlands 5 I (2009): 77-89; Jähnig, Verfassung und Verwaltung, I 60-220.

19 Herrmann, Der Deutsche Orden, 240-241, 272-274; Jähnig, Verfassung und Verwaltung, I 34-I 35; Kreem, "Der Deutsche Orden in Livland," 79-8 I. 
Generell lässt sich sagen, dass bis zum I 5 . Jahrhundert direkte Kontakte zwischen dem livländischen und dem deutschen Ordenszweig sehr selten waren. Anders als die livländischen Prälaten von Riga, Dorpat und Ösel, die schon seit dem I 3 . Jahrhundert Reichsfürsten waren, hatte der livländische Zweig weder offizielle noch direkte Beziehungen mit dem Reich. ${ }^{20}$ Das Potenzial für gegenseitige Beziehungen begann erst dann zu wachsen, als sich die Beziehungen des Deutschen Ordens mit dem Reich im Allgemeinen intensivierten und die deutschen und die livländischen Ordensleute versuchten, ihre Eigeninteressen selbstbewusster durchzuführen. ${ }^{21}$ Eine direkte politische Zusammenarbeit gab es beim Konflikt zwischen Hochmeister Paul von Rusdorf (I 422-I 44I) und dem Deutschmeister..$^{22}$ Damals wurde der vom Hochmeister nicht konfirmierte livländische Meisterkandidat Heidenreich Vincke von Overberg (I438/I44I-I450) vom Deutschmeister aufgrund der sogenannten Orselnschen Statuten bestätigt. ${ }^{23}$ Jedoch blieb diese Kooperation Episode. ${ }^{24}$ Ein anderes Mal stellten der deutsche und der livländische Meister sich gegen die hochmeisterliche Politik während der Amtszeit Albrechts von Brandenburg-Ansbach ( I 5 I I-I 525 ). ${ }^{25}$ Diese Zusammenarbeit hatte den Hochmeister so sehr beunruhigt,

20 Die Bischöfe von Riga, Dorpat und Ösel wurden in den I 22oer Jahren Lehnsmänner des Kaisers, vgl. Mäesalu, Liivimaa ja Püha Rooma keisririik, 53-83. Über die Beziehungen des Ordenszweiges zum Reich bis I 486: ebd., 89-94, 100-I I 3, I 35-I 47, I62-I66.

${ }_{21}$ Hofmann, Der Staat des Deutschmeisters, 77- 05 ; Johannes Götz, "Verbunden mit der Marienburg. Livländischer und preußischer Deutschordenszweig bis zum Ausbruch des Zungenstreits I 438," in Livland - eine Region am Ende der Welt?, hrsg. v. Selart und Thumser, 37 I -4 I 4; ders., "Die Wahl des livländischen Meisters," 4 I- 52.

22 August Seraphim, "Zur Geschichte und Kritik der angeblichen Statuten des Hochmeisters Werner von Orseln," Forschungen zur brandenburgischen und preußischen Geschichte 28 ( 19 I 5 ): I-82; Carl A. Lückerath, Paul von Rusdorf, Hochmeister des Deutschen Ordens 1422-I44I, Quellen und Studien zur Geschichte des Deutschen Ordens is (Bonn-Bad Godesberg: Verlag Wissenschaftliches Archiv, I 969), 173-183.

23 Seraphim, "Zur Geschichte und Kritik," I 6; über den Konflikt in Livland siehe Sonja Neitmann, Von der Grafschaft Mark nach Livland: Ritterbrüder aus Westfalen im livländischen Deutschen Orden, Veröffentlichungen aus den Archiven Preußischer Kulturbesitz 3 (Köln: Böhlau, I 993), 54-I 70; Götz, "Die Wahl des livländischen Meisters," 4 I-45.

24 Die Livländer unterstützten den deutschen Zweig während der folgende Dispute mit den Hochmeistern in der Regel nicht. Vgl. Klaus-Eberhard Murawski, Zwischen Tannenberg und Thorn. Die Geschichte des Deutschen Ordens unter dem Hochmeister Konrad von Erlichshausen I44I-1449, Göttinger Bausteine zur Geschichtswissenschaft Io/ı I (Göttingen: Musterschmidt, I 953), 35-43; Seraphim, "Zur Geschichte und Kritik," 30-36.

25 Erich Joachim, Die Politik des letzten Hochmeisters in Preussen, Albrecht von Brandenburg, I. Theil, I5I0-I5I7, Publikationen aus den königlich-preußischen Staatsarchiven 50 (Leipzig: Hirzel, I 892 ); ders., Die Politik des letzten Hochmeisters in Preussen, Albrecht von Brandenburg, 2. Theil, I5I8-I52I, Publikationen aus den königlich-preußischen Staatsarchiven 58 (Leipzig: Hirzel, I 894); ders., Die Politik des letzten Hochmeisters in Preußen Albrecht von Brandenburg, 3. Theil, I52I-I525, Publikationen aus den königlich-preußischen Staatsarchiven 6I (Leipzig: 
dass er Anfang 1519 den deutschmeisterlichen Kanzler Balthasar Dörelin verhaften und verhören ließ, als er aus Livland zurückkehrte. ${ }^{26}$ Auch später war er über die Kooperation der Zweige oft besorgt. ${ }^{27}$ Allerdings war aber auch diese Zusammenarbeit nicht dauerhaft - die Kompromisse mit dem Hochmeister hatten beide Zweige während des Jahreswechsels I 524/ 525 gesondert und wohl ohne nähere gegenseitige Konsultation abgeschlossen. ${ }^{28}$

Zusätzlich zu diesen konkreten Konflikten mit dem Hochmeister hatte der livländische Meister nur ausnahmsweise direkt mit dem deutschen Zweig kooperiert. Vielleicht das beste Beispiel dafür ist der Versuch des livländischen Meisters Bernd von der Borch ( I 47 I - I 483), die Reichsregalien des Erzbistums Riga zu erwerben. Der Hochmeister war gegen diesen Plan, aber der deutsche Zweig war bereit, die Verhandlungen der Gesandten des livländisches Meisters im Reich zu fördern. ${ }^{29}$ Nach Borchs Versuch kehrten die Livländer aber zur alten Methode zu-

Hirzel, I 895); Kurt Forstreuter, Vom Ordensstaat zum Fürstentum. Geistige und politische Wandlungen im Deutschordensstaate Preußen unter den Hochmeistern Friedrich und Albrecht (1498-1525) (Kitzingen: Holzner, 1951); Walter Hubatsch, Albrecht von Brandenburg-Ansbach, Deutschordens-Hochmeister und Herzog in Preußen 1490-1568, Studien zur Geschichte Preußens 8 (Heidelberg: Quelle \& Meyer, 1960).

26 Handlingar till Nordens historia I5IS-I523, Bd. II, juli I5I8-december I5I9, Tl. I, juli-december I5I8, hrsg. v. Lars Sjödin, Historiska handlingar 2 (Stockholm: Norstedt, I 977), I I 2 - I I 4 Nr. 709, I3 I-I 34 Nr. 725 ; Handlingar till Nordens historia I515-1523, Bd. II, Juli I5I8 - december I5Ig, Tl. 2, I5Ig, hrsg. v. Lars Sjödin, Historiska handlingar 2 (Stockholm: Norstedt, 1 979), $193-204$ Nrn. 764-767, 2 I 3-2 I 5 Nrn. 775-776, 740-75 I Nr. I 175.

27 I 522 fingen die Leute des Hochmeisters einen Brief des Deutschmeisters an den livländischen Meister mit dem Vorschlag, die Kooperation gegen den Hochmeister zu intensivieren, ab, vgl. Joachim, Die Politik, 3: 20 I Nr. 53; siehe auch: Pfleger zu Tilsit an Hochmeister, Mai I 522 , Berlin, Geheimes Staatsarchiv Preußischer Kulturbesitz, XX. HA, Ordensbriefarchiv (weiterhin als: GStA PK, XX. HA, OBA), Nr. 255 I 5 a. Zur Haltung der preußischen Ordensspitze zur Kooperation zwischen dem deutschen und dem livländischen Meister siehe auch: Notizen für die Behandlung der auswärtigen Politik des Hochmeisters durch Dietrich von Schönberg und Klingenbeck, 8. September I 52 I, GStA PK, XX. HA, OBA, Nr. 25056; Hochmeister an Dietrich von Schönberg, 27. September 1521, Königsberg, GStA PK, XX. HA, OBA, Nr. 25095; Instruktionen für den Prokurator Georg Pusch (Busch), I 2. Oktober I 52 I, GStA PK, XX. HA, OBA, Nr. 25 I 22; Dietrich von Schönberg an Hochmeister, I6. Januar I 522 , Lübeck, GStA PK, XX. HA, OBA, Nr. 25292; Deutschmeister an Meister in Livland, 24. April I 522 , Nürnberg, GStA PK, XX. HA, OBA, Nr. 2545 6; Dr. Georg Posch, Prokurator, an Hochmeister, 17. März 1 523, GStA PK, XX. HA, OBA, Nr. 26002; Fischhausen, Bischof Georg von Samland an Hochmeister, 3. Februar I 524, GStA PK, XX. HA, OBA, Nr. 26706 ; Hochmeister an Georg von Klingenbeck in Spanien, 23. November 1524, Ansbach, GStA PK, XX. HA, OBA, Nr. 27349; Joachim, Die Politik, 3: I 6 I- I 66 Nr. 26, I 8 I , Nr. 4 I.

28 Joachim, Die Politik, 3: 349-353 Nrn. 205-206, 359-368 Nrn. 208-209.

29 Borchs anfänglich erfolgreiche Politik endete jedoch mit eine Niederlage. Vgl. Klaus Neitmann, "Um die Einheit Livlands. Der Griff des Ordensmeisters Bernd von Borch nach dem Erzstift 
rück: Als Meister Wolter von Plettenberg (I 494-1 535) während der I 490er und I 5 ooer Jahre vom Reich Unterstützung gegen Russland suchte, kommunizierte er meistens über den Hochmeister, während er Kontakt mit dem Deutschmeister im Einvernehmen mit dem Ordensoberhaupt aufnahm. ${ }^{30}$

Die größte objektive Behinderung einer effektiven gegenseitigen Kommunikation war aber die geographische Entfernung. Während der Hochmeister und der livländische Meister ziemlich schnell korrespondieren und sich gegebenenfalls auch treffen konnten, ${ }^{31}$ war die persönliche Zusammenkunft der deutschen und livländischen Meister praktisch unmöglich; sogar die Korrespondenz konnte Monate dauern, insbesondere wenn der Seeweg im Winter unbenutzbar war und nachdem der Landweg wegen der Säkularisation Preußens unsicher geworden war. ${ }^{32}$ Dabei sollte man jedoch betonen, dass Lübeck und besonders das Ordenshaus in der Stadt, das schon früher ein sehr wichtiger Knotenpunkt für Livlands Kommunikation mit dem Reich gewesen war, nach der Säkularisation Preußens noch wichtiger wurde. ${ }^{33}$ Jedenfalls nutzte der deutsche Zweig die Entfernung Livlands als Argument dafür, es nicht in seine Pläne einzubeziehen. ${ }^{34}$

Riga um I 480," in Deutsche im Nordosten Europas, hrsg. v. Hans Rothe, Studien zum Deutschtum in Osten 22 (Köln-Wien: Böhlau, I991), I09-1 37; Jörg Schwarz, "Zwischen Kaiser und Papst. Der Rigaer Erzbistumsstreit I 480-I 483," Zeitschrift für historische Forschung 34 (2007): 373-402; Alexander Baranov, "Zwischen Bündnis und Konfrontation. Der livländische Ordensmeister Bernd von der Borch und Großfürst Ivan III. von Moskau (1471-1483)," in Akteure mittelalterlicher Außenpolitik. Das Beispiel Ostmitteleuropas, hrsg. v. Stephan Flemming und Norbert Kersken, Tagungen zur Ostmitteleuropaforschung 35 (Marburg: Herder, 2017), I 27-I 44; Jaron Sternheim, "Politische Akteure zwischen päpstlicher Kurie und Livland. Das Beispiel Stephan Grube, Erzbischof von Riga ( $1480-1483)$," in Livland - eine Region am Ende der Welt?, hrsg. v. Selart und Thumser, 237-258.

30 Wimmer, "Livland - ein Problem," 75.

${ }^{31}$ Hartmut Boockmann, "Die Briefe des Deutschordenshochmeisters," in Kommunikationspraxis und Korrespondenzwesen im Mittelalter und in der Renaissance, hrsg. v. Hans-Dieter Heimann und Ivan Hlaváček (Paderborn: Schöningh, I998), I03-I 2.

32 Zu geographischen und klimatischen Problemen der Verbindung zwischen Livland und Norddeutschland: Juhan Kreem, "Seasonality of Transport Network in the Eastern Baltic," in Towns and Communication, vol. II, Communication between Towns, hrsg. v. Hubert Houben und Kristjan Toomaspoeg, Saggi e Testi / Università Degli Studi Del Salento, Dipartimento Dei Beni Delle Arti e Della Storia 45 (Galatina: Congedo, 201 I), 259-269; Madlena Mahling, "Raum und Zeit im Briefverkehr der livländischen Hansestädte mit Lübeck (1 450-I 500)," in Livland - eine Region am Ende der Welt?, hrsg. v. Selart und Thumser, 9 I - 140.

33 Juhan Kreem, "Die Lübecker in der Kommunikation des Deutschen Ordens im I 6. Jahrhundert," in "Hansisch" oder "nicht-hansisch". Das Beispiel der kleinen Städte und Livlands in der Hanse, hrsg. v. Juhan Kreem und Jürgen Sarnowsky, Hansische Studien 27 (Wismar: Callidus, 2019), 97-1 I0.

34 Ende 1524 hatten die deutschen Ordensleute beschlossen, Livland über die nächsten Ordenskapitel in Deutschland "besser nicht zu benachrichtigen, da der Landweg durch Polen und 


\section{REICHSTAGSFÄHIGKEIT}

Um die Wende zum i6. Jahrhundert änderte sich das Verhältnis der Ordenszweige zum Reich entscheidend. Obwohl der Deutschmeister schon seit dem I 3. Jahrhundert oft zum engsten Kreis um den Kaiser bzw. König gehörte und auch an den Reichsversammlungen und Reichsabgaben beteiligt war, wurde seine faktische Stellung als unmittelbares, königsnahes Reichsglied erst I 494 mit der Verleihung des Reichsfürstenstandes formalisiert. Dies bedeutete auch ein festes Sitz- und Stimmrecht auf den Reichstagen. ${ }^{35}$ Der Hochmeister dagegen wurde schon seit den I 440er Jahren als ein Fürst des Reiches auch zu Reichsversammlungen eingeladen, jedoch wurde dieses Verhältnis hauptsächlich wegen des fehlenden Interesses des Ordenshaupts, sich direkt mit dem Reich zu verbinden, nicht zum Reichsfürstenstand formalisiert. ${ }^{36}$

Schon auf dem Reichstag von I 495 hatte König Maximilian I. den livländischen Meister als dem erwirdigen, unnserm und des reichs fursten und lieben andechtigen bezeichnet, ${ }^{37}$ doch erst seit dem Reichstag von I 500 gibt es konkretere Hinweise auf Pläne, sowohl den Hochmeister als auch den livländischen Meister mit den Reichsregalien zu belehnen. ${ }^{8}$ Weitere fünf Jahre später schickte der livlän-

Preußen unsicher und die Seeverbindung blockiert" war (Hofmann, Der Staat des Deutschmeisters, I 68). I 525 behauptete der Obermarschall Georg von Eltz, dass eine Reise nach Livland etwa ein halbes Jahr dauere und deswegen der Deutschmeister ohne Konsultation mit dem Livländer die Hochmeisterwürde auf sich nehmen solle (Herrmann, Der Deutsche Orden, 39).

35 Karl Borchardt, "Die Erhebungen zum Reichsfürsten für den Deutschmeister I 494 und für den Johannitermeister i 548," in Von Hamburg nach Java, hrsg. v. Jochen Burgtorf, Christian Hoffarth, und Sebastian Kubon, Nova Mediaevalia I 8 (Göttingen: Vandenhoeck und Ruprecht, 2020), 427-442; Hofmann, Der Staat des Deutschmeisters, 106 - I 13.

36 Vgl. Ottokar Israel, Das Verhältnis des Hochmeisters des Deutschen Ordens zum Reich im Is. Jahrbundert, Wissenschaftliche Beiträge zur Geschichte und Landeskunde Ost-Mitteleuropas 4 (Marburg/Lahn: Herder-Institut, I952); Marian Biskup, "Der Deutsche Orden im Reich, in Preußen und Livland im Banne habsburgischer Politik in der zweiten Hälfte des I 5 . und zu Beginn des 16. Jahrhunderts," in Die Ritterorden zwischen geistlicher und weltlicher Macht im Mittelalter, hrsg. v. Zenon H. Nowak, Ordines Militares. Colloquia Torunensia Historica V (Toruń: Wydawnictwo Uniwersytetu Mikołaja Kopernika, I 990), I 1 I - 25.

37 Liv-, Est-und Kurländisches Urkundenbuch, Abt. 2, Bd. I, I494 Ende Mai- I5oo, hrsg. v. Leonid Arbusow, sen. (Riga-Moskau: Deubner, I 900), I 85 Nr. 247; vgl. ebd., I 87 Nr. 249. Die Reichsstände setzten dies nicht fort und nannten den Meister einfach einen Fürsten, vgl. ebd., I 86 Nr. 248, I 88 Nr. 250.

${ }_{38}$ Neue und vollständigere Sammlung der Reichs-Abschiede, Welche von den Zeiten Kayser Conrads II. bis jetzo, auf den Teutschen Reichs-Tägen abgefasset worden, sammt den wichtigsten ReichsSchlüssen, so auf dem noch fürwährenden Reichs-Tage zur Richtigkeit gekommen sind, Bd. 2, Reichs-Abschiede von dem Jahr I495. bis auf das Jahr I55I. inclusive, hrsg. v. Heinrich Christian von Senckenberg und Johann Jacob Schmauss (Frankfurt/Main: Koch, 1747), 83. 
dische Meister seine eigene Gesandtschaft an Maximilian I. und bat um Hilfe der Reichstagsteilnehmer gegen die Russen. ${ }^{39}$ Der König verlieh dem livländischen Zweig ein dreijähriges Zollprivileg, ${ }^{40}$ das er versprach, in ein immerwährendes umzuwandeln, falls der livländische Meister die Reichsregalien erhalte. ${ }^{41}$ Für diesen Schritt benötigte der Meister die Zustimmung des Hochmeisters, der jedoch verärgert reagierte, weil der Meister direkt mit dem König und den Reichsständen kommuniziert hatte, ohne ihn zu benachrichtigen..$^{42}$ Später versuchte der Meister, die Zusage des Hochmeisters zu erhalten, und der nächste Hochmeister, Markgraf Albrecht, war zumindest formell bereit, die livländischen Bemühungen beim Kaiser zu unterstützen. ${ }^{43}$ Bis I 52 I scheint sich in der Sache jedoch nicht viel bewegt zu haben. ${ }^{44}$ Danach aber empfingen alle livländischen Bischöfe Reichsregalien, ${ }^{45}$ und

39 Der Reichstag zu Köln I sos, Tlbd. I-2, hrsg. v. Dietmar Heil, Deutsche Reichstagsakten. Mittlere Reihe 8 (München: Oldenbourg, 2008), 827-829 Nr. 506.

$4 \circ$ Liv-, Est-und Kurländisches Urkundenbuch, Abt. 2, Bd. II, I50I-I505, hrsg. v. Leonid Arbusow, sen. (Riga-Leipzig: Deubner, I 905), 628-630 Nr. 8 I 2.

4 Ebd., 630 Nr. 8 I 3.

42 Zusätzlich fürchtete der Hochmeister für Preußen die wirtschaftlichen Nachteile des livländischen Zollprivilegs, vgl.-Regesta historico-diplomatica Ordinis S. Mariae Theutonicorum, IIg8-I525, pars I, Index Tabularii Ordinis S. Mariae Theutonicorum. Regesten zum Ordensbriefarchiv, vol. 3, ISII-I525, hrsg. v. Erich Joachim und Walter Hubatsch (Göttingen: Vandenhoeck und Ruprecht, I973), Nr. 19061; Der Reichstag zu Köln I505, hrsg. v. Heil, 829.

43 Der Reichstag zu Worms I 509, hrsg. v. Dietmar Heil, Deutsche Reichstagsakten. Mittlere Reihe Io (Berlin-Boston: De Gruyter Oldenbourg, 2017), I 49-I 50 Nr. 20; Das virtuelle Preußische Urkundenbuch: Regesten und Texte zur Geschichte Preußens und des Deutschen Ordens, hrsg. v. Jürgen Sarnowsky, I999-202 I, DH 88, Dieter Heckmann, letzte Änderung I 3. August 2002, zugegriffen am 26. Februar $202 \mathrm{I}$, http://www.spaetmittelalter.uni-hamburg.de/Urkundenbuch/pub/dh/dh88.htm; ebd., DH 92, ders. letzte Änderung 31. August 2002, zugegriffen am 26. Februar 202 I, http://www.spaetmittelalter.uni-hamburg.de/Urkundenbuch/pub/dh/ dh92.htm; ebd., DH 93, ders., letzte Änderung 30. September 2002, zugegriffen am 26. Februar 202 I, http://www.spaetmittelalter.uni-hamburg.de/Urkundenbuch/pub/dh/dh93.htm. Über die Erörtung die Zollfrage in Livland: Akten und Rezesse der livländischen Ständetage, Bd. 3 , 1494-1535, hrsg. v. Leonid Arbusow, sen. (Riga: Deubner, I910), 26, 30-3 I Nr. 35, 635, 638 Nr. 245 .

44 Möglicherweise wollte der livländische Meister nur das Zollprivileg erhalten und den Regalienempfang vermeiden, vgl. Hochmeister an Wolter von Plettenberg, 4. August I 5 I I, Ansbach, GStA PK XX. HA OBA, Nr. 19457; Meister von Livland an Hochmeister, 24. März I 5 I 3 , Wenden, GStA PK XX. HA OBA, Nr. 19727; Nordosteuropa, hrsg. v. Wieser, 33 Nr. 171, 36 Nr. 194.

45 Die Beschwerden der deutschen Nation auf den Reichstagen der Reformationszeit (I52I-I530), hrsg. v. Annelies Grundmann und Rosemarie Aulinger, Deutsche Reichstagsakten. Jüngere Reihe: Deutsche Reichstagsakten unter Kaiser Karl V. 2 I (München: De Gruyter, 20 I 5 ), I 48 |-149; Hermann Hildebrand, Die Arbeiten für das Liv-, Est- und Kurländische Urkundenbuch im Jahre 1875/76 (Riga: Müller, I 877), 93-98; Maasing, "Livland und die Reichstage," 287-289. 
auch der Hochmeister begann, sich nach der Niederlage im Reiterkrieg (I 19 9-I 52 I) um die Reichsregalien zu bemühen. ${ }^{46}$ Auch der livländische Meister bat den Hochmeister, die Gewährung der Regalien intensiver zu unterstützen. ${ }^{47}$ Bis I 525 erhielt Hochmeister Albrecht wahrscheinlich eine prinzipielle Zusage des Kaisers und der Reichsstände für eine zukünftige preußische Regalienverleihung, ${ }^{48}$ aber livländische Interessen hatte er dabei nicht besonders eifrig verfolgt, vielleicht mit einem Hintergedanken, um seine Position hinsichtlich Livlands zu verbessern. Deshalb erklärten die livländischen Ordensleute, dass sie die Sache selbst weiter vorantreiben wollten, wenn der Hochmeister die Regalien innerhalb eines Jahres nicht erlangen könne. ${ }^{49}$

Da die Säkularisation Preußens im April 1525 stattfand, blieb dem livländischen Zweig keine andere Möglichkeit, als den Regalienerwerb selbst weiterzuführen. Dafür hatte der livländische Meister die Unterstützung des deutschen Zweigs umfassend genutzt: Im Sommer I 525 schickte der Meister seine Gesandten zum Deutschmeister, deponierte Geld für den Regalienerwerb beim Hauskomtur von Nürnberg und ordnete an, dass von diesem Geld auch der deutschmeisterliche Kanzler Dörelin bezahlt werden solle, der offensichtlich mit der Regaliensache beschäftigt war..$^{\circ \circ}$

Den Fortgang des Regalienerwerbs, bei dem der deutsche Zweig die Kontakte zum Kaiser und dem Reichsregiment aktiv unterstützte, hat Bernhard Demel de-

${ }^{6}$ Vgl. Herrmann, Der Deutsche Orden, 2 I-23.

47 Vgl. Instruktion für Roebell [Sekretär des livländischen Meisters], I I. Juli I 52 I, Wenden, GStA PK, XX. HA, OBA, Nr. 2497 I; Bescheid des Hochmeisters für den livländischen Sekretär Peter Robel, 24. Juli I 52 I, GStA PK, XX. HA, OBA, Nr. 24985; Notizen für die Behandlung der auswärtigen Politik des Hochmeisters durch Dietrich von Schönberg und Klingenbeck, 8. September I 52 I, GStA PK, XX. HA, OBA, Nr. 25056; Meister in Livland an Hochmeister, I o. September I 52 I, Wenden, GStA PK, XX. HA, OBA, Nr. 25072 ; Hochmeister an Markgraf Hans, 20. Januar I 523 , Nürnberg, GStA PK, XX. HA, OBA, Nr. 25904; Instruktion für Wolf von Heydeck und Michel von Drahe zu ihrer Mission nach Livland u.a. Dokumente, I 523 , GStA PK, XX. HA, OBA, Nr. 26572; Friedrich von Heydeck und Christopher Gattenhofer an Hochmeister, I. Februar I 524, GStA PK, XX. HA, OBA, Nr. 26705; Graf Georg zu Ortenburg an Hochmeister, 16. September I 524, Wien, GStA PK, XX. HA, OBA, Nr. 27226; Joachim, Die Politik, 3, Nrn. 20-2 I, 26, I I 2-I I 4; Das virtuelle Preußische Urkundenbuch, hrsg. v. Sarnowsky, DH 427, Dieter Heckmann, letzte Änderung 27. September 20 I 2, zugegriffen am 8. März 202 I, http://www.spaetmittelalter.uni-hamburg.de/Urkundenbuch/pub/dh/dh427.htm.

48 Herrmann, Der Deutsche Orden, 2 I -23.

49 Michael Drahe an Hochmeister: Bericht über seine Verhandlungen in Livland, 26. Januar I 525 , Memel, GStA PK, XX. HA, OBA, Nr. 275 I 4; Joachim, Die Politik, 3: 366-368, Nr. 209.

so Nordosteuropa, hrsg. v. Wieser, 43 Nrn. 264-265, 49 Nr. 324; Die Urkunden des Deutschordenszentralarchivs in Wien: Regesten. Tlbd. III, Dezember 1418 - Dezember I526, hrsg. v. Marian Tumler und Udo Arnold, Quellen und Studien zur Geschichte des Deutschen Ordens 6o/III (Marburg: Elwert, 2007), I 406 Nr. 490 I. 
tailliert dargestellt. Das braucht hier nicht wiederholt zu werden. ${ }^{51}$ Jedoch scheint seine Datierung der Regalienverleihung auf den 24. Dezember I 527 eher unwahrscheinlich. Dieses Datum erscheint in mehreren Abschriften und Darstellungen, jedoch gibt es auch solche, die Jahreszahl i 526 enthalten, und da man den Jahresbeginn im I 6. Jahrhundert nicht unbedingt mit dem I. Januar ansetzen muss, sind beide Datierungen möglich. Zudem ist es ganz offensichtlich, dass alle erforderlichen Prozeduren für den Regalienempfang bis Ende I 526 durchgeführt worden waren und der Bischof Hermann von Kurland (1 524-1 539), ein Gesandter des Meisters, seine eigenen Regalien am 24. Dezember I 526 erwarb. ${ }^{52}$ Auch berichtete Erzbischof Johann Blankenfeld von Riga, ein anderer Gesandter des Meisters, im April I 527 vom Reichstag zu Regensburg an den Meister, dass die Gesandten des Meisters, Bischof Hermann von Kurland und der livländische Kanzler Friedrich Schneeberg, die Regalien erhalten hätten. Wenig später erörterte Blankenfeld auch die Bedingungen der empfangenen Regalien. ${ }^{53}$ Es ist kaum zu glauben, dass er nur über die kurländischen Regalien sprach. Damit wird es sehr wahrscheinlich, dass der livländische Meister den Regalienbrief schon am 24. Dezember I 526 vom Reichsregiment erhielt. Danach hatte er zumindest theoretisch die Möglichkeit, an Reichstagen teilzunehmen.

\section{Teilnahme an Den Reichstagen}

Obwohl Ordensgesandtschaften schon seit dem Ende des I 4. Jahrhunderts an Reichsversammlungen teilgenommen hatten, ${ }^{54}$ kann man die Teilnahme der Ordenszweige als Reichsglieder erst ab dem Reichstag von Augsburg (I 495) zählen, den der gefürstete Deutschmeister besuchte. Auch die nächsten Reichstage hatten er oder seine Gesandten regelmäßig aufgesucht. ${ }^{55}$ Die anderen Ordenshäupter ka-

sI Demel, "Zur Reichspolitik," I 5 I- I 57.

52 Ebd., 153.

53 Deutsche Reichstagsakten unter Kaiser Karl V., Bd. 7, hrsg. v. Johannes Kühn, Deutsche Reichstagsakten. Jüngere Reihe: Deutsche Reichstagsakten unter Kaiser Karl V. 7 (Göttingen: Vandenhoeck und Ruprecht, 1935), 50.

$\$ 4$ Boockmann, "Die Vertretung des Deutschen Ordens."

ss Von I 495 bis I 5 I 8 war meistens Vertreter anwesend, vor allem Johann Adelmann von Adelmannsfelden (von I 497 bis I 5 I 2, zuerst als Komtur von Blumenthal, dann als Komtur von Mergentheim (1508-1510) und zuletzt als Deutschmeister, 1510-1515). Von 22 Reichstagen in den Jahren I 52 I bis 1559 war der Deutschmeister nur bei sieben nicht persönlich anwesend. Vgl. Bernhard Demel, "Die Reichstagsgesandten des Deutschen Ordens von I 495 bis Ende r 805," in ders., Der Deutsche Orden im Spiegel, 607-6r 4; Rosemarie Aulinger und Silvia Schweinzer-Burian, Habsburgische und reichsständische Präsenz auf den Reichstagen 
men viel seltener zu den Reichstagen. Von den Hochmeistern hatte nur Albrecht von Brandenburg-Ansbach zwei Nürnberger Reichstage ( I $522 /$ I 523 und I 524 ) als ein Reichsglied besucht und dabei auch einen sehr hervorgehobenen Sitz erhalten (nach den Kurfürsten und vor allen Erzbischöfen, außer dem von Salzburg)..$^{56}$ Auf dem zweiten dieser Reichstage fand aber auch der Sessionstreit zwischen dem Hoch- und dem Deutschmeister statt, wobei Letzterer seine Position als langjähriger Reichsfürst und die fehlende offizielle Reichsstandschaft des Hochmeisters betonte und erklärte, dass er dem Hochmeister nur ordens-, aber nicht reichsrechtlich unterstellt sei. ${ }^{57} \mathrm{Zu}$ dieser Zeit war die Position des Deutschmeisters in der Reichstagssession recht niedrig, aber ab i 529 konnte er als Administrator des Hochmeistertums Albrechts früheren Sitz hinter dem Erzbischof von Salzburg belegen. ${ }^{8}$ Zwar versuchte auch der preußische Herzog, eine formelle Position auf dem Reichstag zu erlangen, doch das scheiterte an der Gegenwehr des Deutsch-

I52I-I55S, 20 I I, 20, 49, 72, I02, I 27, I 54, I 88, zugegriffen am 8. März 202 I, https://www. historischekommission-muenchen.de/fileadmin/user_upload/MIGRATION_BACKUP/ pdf/abteilungen/staendetabelle_I 52 I_I 555 .pdf

56 Hochmeister Friedrich von Sachsen besuchte den Reichstag zu Worms (I 509), aber er wurde dabei nicht ausdrücklich wegen seine Hochmeisterwürde als ein Reichsstand betrachtet, eher konnte er teilnehmen als ein geborener Reichsfürst (vgl. Der Reichstag zu Worms 1509). Zu Albrechts Aktivitäten auf den Reichstagen von $1522 /$ I 523 : Deutsche Reichstagsakten unter Kaiser Karl V., Bd. 3, hrsg. v. Adolf Wrede, Deutsche Reichstagsakten. Jüngere Reihe: Deutsche Reichstagsakten unter Kaiser Karl V. 3 (Gotha: Perthes, I 901 ), 284, 31 6, 756, 808, 81 6, 842. Über seine Argumentation für einen hohen Sitz: Joachim, Die Politik, 3: 2 I 6-2 I 8 Nrn. 78-80. Auf dem Reichstag zu Nürnberg (1 524 ) vertrat der Hochmeister die Kurfürsten von Mainz und Brandenburg und spielte deshalb eine zentrale Rolle in allen wichtigen Verhandlungen: Deutsche Reichstagsakten unter Kaiser Karl V., Bd. 4, hrsg. v. Adolf Wrede, Deutsche Reichstagsakten. Jüngere Reihe: Deutsche Reichstagsakten unter Kaiser Karl V. 4 (Gotha: Perthes, 1 905 ), 4, 6, 49, 53, 77, 98-I04, I 42-I 43, I 60-I6I, I 7 I, I 76-2 I 2, 249, 269, 296, 30I-303, 338-364, 377-382, 41 9-420, 430, 435-45 I, 502-505, 545-547, 569-570, 582-583, 610, 61 3, 770, 788. Über den Konflikt zwischen Polen und dem Orden wurde auf dem Reichstag aber kaum gesprochen (ebd., 205, 296, 301, 442). Über den Sessionstreit: ebd., 566-570; Joachim, Die Politik, 3: 62, 84, 292-302 Nrn. 1 59-164. Früher wurde der Deutschmeister nicht zu den geistlichen Fürsten (die den zweiten Rang nach den Kurfürsten bekleideten) gezählt, sondern zu den Prälaten (nach den weltlichen Fürsten, also als vierter Rang). Über die Rangerhöhung des Deutschmeisters wurde schon vor dem Reichstag zu Speyer 1529 diskutiert (Deutsche Reichstagsakten unter Kaiser Karl V, 7, hrsg. v. Kühn, 46I), und im Abschied desselben Reichstages wurde er schon nach dem Erzbischof von Salzburg erwähnt (ebd., I 309). Allerdings gab es auch später einige Streitigkeiten um seine Session (Der Reichstag zu Speyer 1542, hrsg. v. Silvia Schweinzer-Burian, Deutsche Reichstagsakten. Jüngere Reihe: Deutsche Reichstagsakten unter Kaiser Karl V. I 2 (München: Oldenbourg, 2003), I I I 3- I I 5; Der Reichstag zu Nürnberg 1542, hrsg. v. Silvia SchweinzerBurian, Deutsche Reichstagsakten. Jüngere Reihe: Deutsche Reichstagsakten unter Kaiser Karl V. I 3 (München: Oldenbourg, 2010), 424). 
meisters. ${ }^{59}$ Trotzdem waren herzogliche Gesandte als Vertreter einer ausländischen Macht oft auf den Reichstagen anwesend. ${ }^{60}$

Es gab noch zwei weitere Ordensbeamte in Deutschland, die reichstagsfähig waren, nämlich die Landkomture von Koblenz und von Elsass-Burgund, deren Balleien kleine reichsunmittelbare Herrschaften enthielten. ${ }^{61}$ Das Recht, am Reichstag teilzunehmen, nahm besonders der Landkomtur von Elsass-Burgund oft wahr, meistens durch Gesandte. An seinen Vertretern kann man aber deutlich sehen, wie wichtig für den Deutschmeister die Administratorwürde war: Bis zum Ende der I $520 e r$ Jahre ließen die Landkomture sich oft gemeinsam mit südwestdeutschen Prälaten vertreten, danach - bis zum Tod Walters von Cronberg (I 543) - wurde der Landkomtur meistens vom Administrator vertreten. ${ }^{62}$

Wegen Livlands Abstand zu den Kernlanden des Reichs ist es nicht verwunderlich, dass der livländische Meister nie persönlich an Reichstagen teilnahm und dass es für ihn auch kompliziert war, Gesandte zu schicken. Die Einladungen zu Reichstagen erreichten Livland normalerweise nicht rechtzeitig, und die Ordensgesandten kamen in der Regel erst zwei bis drei Monate nach Eröffnung

59 Vgl. Herrmann, Der Deutsche Orden, 83-97; Deutsche Reichstagsakten unter Kaiser Karl V., 7, hrsg. v. Kühn, 503; Der Reichstag in Regensburg und die Verhandlungen über einen Friedstand mit den Protestanten in Schweinfurt und Nürnberg I532, Tl. I-3, hrsg. v. Rosemarie Aulinger, Deutsche Reichstagsakten. Jüngere Reihe: Deutsche Reichstagsakten unter Kaiser Karl V. Io (Göttingen: Vandenhoeck \& Ruprecht, 1992), 730-736.

60 Die Gesandten Herzog Albrechts schrieben oft lange Berichte, die auch in den Publikationen der Deutschen Reichstagsakten benutzt sind. Vgl. z.B. Der Reichstag zu Augsburg I525, der Reichstag zu Speyer I526, der Fürstentag zu Esslingen I526, hrsg. v. Rosemarie Aulinger, Deutsche Reichstagsakten. Jüngere Reihe: Deutsche Reichstagsakten unter Kaiser Karl V. 5/6 (München: Oldenbourg, 20 I I), 73, 97-1 00; Deutsche Reichstagsakten unter Kaiser Karl V., 7, hrsg. v. Kühn, 43, 81, 175-176, I 82, I94, I97, 202, 208-209, 503, 51 5-516, 532, 632, 852 , I 09 I; Der Reichstag zu Regensburg I54I, hrsg. v. Albrecht P. Lutterberger und Christiane Neerfeld, Deutsche Reichstagsakten. Jüngere Reihe: Deutsche Reichstagsakten unter Kaiser Karl V. I I (Berlin-Boston: De Gruyter Oldenbourg, 2018), 472-473, I080, I 583-I 6 I 3, I 658-1665, I 668-1683, I 697-1 703, 2 I I 5-2 I I 9, 2 I 45-2 I 49, 2 I 77, 24 I 9, 2464-2466, 2672-268 I, 2953-2956; Der Speyrer Reichstag von I544, Tl. I-4, hrsg. v. Erwein Eltz, Deutsche Reichstagsakten. Jüngere Reihe: Deutsche Reichstagsakten unter Kaiser Karl V. I 5 (Göttingen: Vandenhoeck \& Ruprecht, 200I), 54; Der Reichstag zu Worms I545, hrsg. v. Rosemarie Aulinger, Deutsche Reichstagsakten. Jüngere Reihe: Deutsche Reichstagsakten unter Kaiser Karl V. I 6 (München: Oldenbourg, 2003), 281, 354, 659, II21, 1519, 1561-1565, 1567-1568, 1619, 1648; Der Reichstag zu Regensburg 1546, hrsg. v. Rosemarie Aulinger, Deutsche Reichstagsakten. Jüngere Reihe: Deutsche Reichstagsakten unter Kaiser Karl V. 17 (München Oldenbourg: 2005), 61, 223, 515 .

${ }_{61}$ Die Herrschaften waren Elsen (Koblenz) und Althausen (Elsass). Vgl. Herrmann, Der Deutsche Orden, I 48-1 49, I 5 I-I 52 .

62 Während der I 55 oer Jahre waren die Landkomture jedoch meistens persönlich anwesend. Vgl. unten: Anhang: Tabelle. 
des Reichstags an. ${ }^{63}$ Trotzdem nahm die erste offizielle Gesandtschaft des livländischen Meisters am Reichstag von Augsburg ( 1530 ) teil, wo der Kaiser dem Deutschmeister die Reichsregalien für Preußen und dem livländischen Meister für Livland verlieh. Von I 544 bis I 559 waren Vertreter des livländischen Meisters auf jedem Reichstag anwesend. Man kann aber sagen, dass die tatsächliche Vertretung des Meisters noch besser war: Der Administrator war auf jedem Reichstag zumindest vertreten und konnte gegebenenfalls im Interesse des Landmeisters handeln. Das tat er zwar meistens nicht formell, weil er nur einmal der offizielle Vertreter des livländischen Meisters war ( I 546), doch hatte er das Nichterscheinen des Meisters mehrmals entschuldigt. ${ }^{64}$ Es sollte erwähnt werden, dass die Livländer in der offiziellen Zusammenarbeit sowohl auf den Reichstagen als auch vor Kaiser oder Papst offenbar keine Vorteile sahen, weil sie Vorschläge des Administrators, eine gemeinsame Sollizitatorstelle vor den beiden Häuptern der Christenheit zu finanzieren, nicht zustimmten; hier aber wohl vor allem wegen der wirtschaftlichen Erwägungen. ${ }^{65}$

Außerdem kann man Erzbischof Johannes Blankenfeld von Riga sowie Bischof Hermann von Kurland als tatsächliche Vertreter des livländischen Meisters auf dem Reichstag von 1527 betrachten, weil beide in seinem Auftrag in Deutschland handelten. Ebenfalls ist zu erwähnen, dass zumindest ein Gesandter des Meisters zur Zeit des Reichstags beim römischen König gewesen war (I 542). Die Tätigkeit dieses Gesandten erweckte auch auf dem Reichstag Aufmerksamkeit. ${ }^{66}$ Gelegentlich konnten Pläne der livländischen Ordensgesandten, die Reichstage zu besuchen, nicht ausgeführt werden. ${ }^{67}$ Der Sitz der livländischen Gesandten war weit hinter dem des Administrators: normalerweise wurden sie ganz am Ende der geistlichen Fürsten platziert. ${ }^{68}$

${ }_{63}$ Es gab einige Ausnahmen, falls die Gesandten in anderen Angelegenheiten schon in Deutschland waren. Maasing, "Livland und die Reichstage," 292.

${ }_{64}$ Zumindest für die Reichstage von 1 529, 1532 und I 54 I: Nordosteuropa, hrsg. v. Wieser, 85 Nr. 636, 90 Nr. 674, 109 Nr. 855 , I 53 Nr. I 267; Der Reichstag in Regensburg, hrsg. v. Aulinger, 235; Herrmann, Der Deutsche Orden, 2 I 7-2 18.

65 Herrmann, Der Deutsche Orden, 2 I 8-2 19.

66 Der Reichstag zu Speyer 1542, hrsg. v. Schweinzer-Burian, 37 I.

${ }_{67}$ Zum Beispiel waren die Ordensgesandten im Jahr I 528 schon im Reich, aber dann wurde der Reichstag abgesagt (Deutsche Reichstagsakten unter Kaiser Karl V., 7, hrsg. v. Kühn, 2 I 0, 22 I).

68 Auf den Reichstagen von I 555 und I 556/ 557 nahmen die Gesandten des Meisters den vorletzten Platz vor den Vertretern des Propsts von Ellwangen ein (Der Reichstag zu Augsburg I555, Tl. I-4, hrsg. v. Rosemarie Aulinger, Erwein Eltz, und Ursula Machoczek, Deutsche Reichstagsakten. Jüngere Reihe: Deutsche Reichstagsakten unter Kaiser Karl V. 20 (München: Oldenbourg, 2009), 3 1 53; Der Reichstag zu Regensburg 1556/57, hrsg. v. Josef Leeb, Deutsche Reichstagsakten. Reichsversammlungen 1556-1662 (München: Oldenbourg, 2013), I412). Im Reichstag von I 547/I 548 wurden sie zwischen den Vertretern der Bischöfe von Basel und 
Wenn man die persönlichen Qualifikationen der Ordensgesandten betrachtet, fällt es auf, dass sowohl die deutschen als auch die livländischen Vertreter meistens erfahrene Diplomaten waren, die schon lange Zeit dem Orden gedient hatten. Mehrere von ihnen machten auch eine bemerkenswerte Ordenskarriere: So wurden die Gesandten Johann Adelmann von Adelmannsfelden, Walter von Cronberg und Wolfgang Schutzbar gen. Milchling später Deutschmeister bzw. Administrator; von den livländischen Gesandten brachte es der Marienburger Komtur Jasper von Münster zum Landmarschall und Rigaer Hauskomtur Georg von Syburg zu Wischlingen zum Komtur von Dünaburg (lett. Daugavpils). ${ }^{69} \mathrm{Ne}-$ ben Ordensmitgliedern reisten auch Fachleute zu den Reichstagen; Ordenskanzler und Sekretäre nahmen oft sowohl an den deutschen als auch den livländischen Gesandtschaften teil. Eine Ausnahme vom allgemeinen Muster bildete der kurländische Ordensvasall Philipp von der Brüggen, der zwei Reichstage (I 547/ I 548 und I 550/i 55 I) besuchte. ${ }^{70}$

Zusätzlich zu Reichstagen waren der Deutschmeister und die Landkomture von Koblenz und dem Elsass übrigens auch auf einer anderen reichsinternen Versammlung präsent, nämlich auf den Reichskreistagen. Dort war ihr Einfluss allerdings sehr begrenzt, und besonders der Deutschmeister hatte auf den Reichstagen viel bessere Möglichkeiten, seine Interessen zu befördern. ${ }^{71}$ Livland gehörte zu keinem Reichskreis, aber die örtlichen Herrschaften versammelten sich zum gemeinem livländischen Landtag, auf dem die wichtigsten Probleme erörtert und entschieden wurden. Im Gegensatz zum deutschen Zweig und den Kreistagen hatten die Landtage für den livländischen Ordenszweig weitaus größere Bedeutung

Cambrai genannt (Der Reichstag zu Augsburg I547/48, Tl. I-3, hrsg. v. Ursula Machoczek, Deutsche Reichstagsakten. Jüngere Reihe: Deutsche Reichstagsakten unter Kaiser Karl V. I 8 (München: Oldenbourg, 2005), 2688). Allerdings war ihre Stellung besser als die des Johannitermeisters und der Balleien von Koblenz und Elsass, die zu den Prälaten (Elsass manchmal auch zu den Grafen und Herren) gezählt wurden.

69 Über Münster: Juhan Kreem, "Netzwerke um Jasper von Munster. Der Deutsche Orden während der livländischen Koadjutorfehde im Jahre i 556," Ordines Militares Colloquia Torunensia Historica. Yearbook for the Study of the Military Orders I9 (2014): 73-86; Johannes A. Mol, "Traitor to Livonia? The Teutonic Orders' land marshal Jasper von Munster and his actions at the outset of the Livonian crisis, I 554-1 5 56," Ordines Militares Colloquia Torunensia Historica. Yearbook for the Study of the Military Orders 19 (20 I 4): 205-240; über Syburg zu Wischlingen: Ritterbrüder im livländischen Zweig des Deutschen Ordens, hrsg. v. Lutz Fenske und Klaus Militzer, Quellen und Studien zur baltischen Geschichte I 2 (Köln-Weimar-Wien: Böhlau, I993), 648-649 Nr. 87 I.

$70 \mathrm{Zu}$ den livländischen Gesandten siehe auch: Maasing, "Livland und die Reichstage," 29 I-295.

${ }_{71}$ Vgl. Herrmann, Der Deutsche Orden, I 33-1 56, 255-257. 
als die Reichstage; zumindest in der Tagespolitik. ${ }^{72}$ Andererseits beeinflussten die Reichstage auch die Landtage seit den $1530 e r$ Jahren, weil mehrere Reichstagsbeschlüsse auf den Landtagen angenommen und dadurch die Verbindungen zwischen Livland und dem Reich gestärkt wurden. ${ }^{73}$

\section{Rekuperation und innerlivländische Probleme auf Den REICHSTAGEN}

Unter den Themen, die mit dem Deutschen Orden direkt verbunden waren, trat die Rekuperationsfrage auf den Reichstagen am häufigsten auf. Schon 1495 wurde das Problem mit den verlorengegangene Ordensgebieten in Italien, die unter dem Deutschmeister standen, auf den Reichstag gebracht. Danach versuchte der Orden, den Anstieg der Spannungen zwischen Livland und Russland auszunutzen und hatte damit anfänglich Erfolg: Die Reichstagsteilnehmer wandten sich an den Papst und König Maximilian an den spanischen Monarchen mit der Bitte, aufgrund der Russengefahr die Ordensbesitzungen zurückzugeben. ${ }^{74}$ Allerdings konnte man die verlorenen Gebiete nicht zurückerhalten, und von I 52 I bis 1530 wurde die Ordensklagen in die antiklerikalen Beschwerden der deutschen Nation (Gravamina nationis Germanicae) aufgenommen - ohne Hinweis auf die russische Bedrohung für Livland, aber genauso vergeblich.75

72 Priit Raudkivi, Der livländische Landtag. Zur Entstehung einer mittelalterlichen Institution, übers. v. Hiltrud Kinnunen, Schriften der Baltischen Historischen Kommission 2 I (Berlin: Lit Verlag, 20I8); Pärtel Piirimäe, "Staatenbund oder Ständestaat? Der livländische Landtag im Zeitalter Wolters von Plettenberg," Forschungen zur baltischen Geschichte 8 (201 3): 40-80; Ilgvars Misāns, "Wolter von Plettenberg und der livländische Landtag," in Wolter von Plettenberg und das mittelalterliche Livland, hrsg. v. Angermann und Misāns, 55-7 I.

73 Beispielsweise bekräftigten die Landtagsteilnehmer die Gültigkeit des Landfriedens von 1495 und die Entscheidung von Speyer aus dem Jahr 1 526, die alle geistliche Fürsten unter Schutz stellte. Zudem wurde die Forderung aus dem Jahr I 530 nach Rückkehr zum Katholizismus angenommen sowie die Reichspolizeiordnung (Maasing, "Livland und die Reichstage," 304-306).

74 Die Reichstagsteilnehmer schilderten, wie der Orden Länder in Russland „mit Blut erkauft“ habe (Reichstag von Worms 1495, Tl. I-3, hrsg. v. Heinz Angermeier, Deutsche Reichstagsakten. Mittlere Reihe 5 (Göttingen: Vandenhoeck \& Ruprecht, I 98 I ), 940 Nr. I 20 I). Maximilian sprach aber über den Großfürsten von Moskau, der sich angeblich mit 300000 Mann an der Grenze Livlands befände (ebd., 94 I Nr. I 202).

75 Über die Verluste in Italien: Kristjan Toomaspoeg, "Der Verlust der Besitzungen des Deutschen Ordens in Italien am Ende des I 5 . und zu Beginn des I 6. Jahrhunderts," Ordines Militares Colloquia Torunensia Historica. Yearbook for the Study of the Military Orders 2 I (2016): I 29- I 54 ; Herrmann, Der Deutsche Orden, 205-2 I 4. Über die Klagen des Ordens in den Beschwerden: Die Beschwerden der deutschen Nation, hrsg. v. Grundmann und Aulinger, 87, I 49, 23 I-235, 3 I 2, 438, 444, 452; Deutsche Reichstagsakten unter Kaiser Karl V., Bd. 2, hrsg. v. Adolf Wre- 
Die Säkularisation Preußens überschattete das italienische Problem nahezu vollständig. Schon auf dem Reichstag von Speyer ( 1526 ) wurde Herzog Albrechts Apologie präsentiert, in der der frühere Hochmeister sowohl den deutschen als auch den livländischen Zweig beschuldigte, Preußen keine nennenswerte Hilfe geleistet zu haben und deshalb mitverantwortlich für die Säkularisation zu sein. ${ }^{76}$ Der Deutschmeister erklärte in seinem Gegenbericht jedoch, dass er und der livländische Meister nichts von den Plänen des abgefallenen Hochmeisters gewusst hätten, dass sie somit keine Schuld an dessen Abfall hätten und dass Preußen nach dem Recht dem Deutschen Orden zurückgegeben werden müsse. ${ }^{77}$ Die beiden Seiten betrieben ihre Polemik intensiv auch außerhalb der Reichstage. ${ }^{78}$

Dank der prinzipiellen und beharrlichen Rekuperationspolitik konnte Walter von Cronberg, der Preußen mit seinem Administratortitel unbedingt verbunden ansah, die Erklärung der Reichsacht sowohl gegen Herzog Albrecht (I 532) als auch gegen die preußischen Stände ( 1536 ) erlangen. ${ }^{79}$ Danach wurde die Rekuperationsfrage ein ständiges Thema auf den Reichstagen, indem einerseits der Orden die Exekution der Acht und die Rückgabe Preußens forderte, andererseits aber die Gesandten des Herzogs und/oder des polnischen Königs die Aufhebung der Acht verlangten. Reichsrechtlich hatte der Orden zweifellos die besseren Argumente, doch der Herzog wurde von vielen protestantischen Fürsten unterstützt, und der Orden konnte sich nur die Unterstützung der Grafen und Reichsritter sichern; jedenfalls war kein Reichsstand bereit, sich an einem Krieg gegen Polen zu beteiligen. Zudem gab Herzog Albrecht Hilfe für die Türkenkriege, was besonders für das kaiserliche Haus Habsburg von zentraler Bedeutung war. ${ }^{80}$ Die Kompro-

de, Deutsche Reichstagsakten. Jüngere Reihe: Deutsche Reichstagsakten unter Kaiser Karl V. 2 (Gotha: Perthes, I 896), 679-680; Deutsche Reichstagsakten unter Kaiser Karl V., 3, hrsg. v. Wrede, 666-667; Der Reichstag zu Augsburg I525, hrsg. v. Aulinger, 670-671; Deutsche Reichstagsakten unter Kaiser Karl V., 7, hrsg. v. Kühn, I 7.

${ }^{6}$ Der Reichstag zu Augsburg I525, hrsg. v. Aulinger, 804-807 Nr. 197.

77 Ebd., 807-809 Nr. 198. Das Ergebnis der Reichstagsdiskussionen war jedoch ungünstig für den Orden, weil der Fürstenrat beschloss, man solle die Ordensklagen zu den italienischen Besitzungen bis zu einer Entscheidung in der preußischen Sache von den Beschwerden der deutschen Nation ausnehmen (ebd., 670-671).

78 Die Apologien Herzog Albrechts, hrsg. v. Almut Bues, Quellen und Studien. Deutsches Historisches Institut Warschau 20 (Wiesbaden: Harrassowitz, 2009); Der Reichstag zu Augsburg I525, hrsg. v. Aulinger, 8 I0-8 I r. Zum Kontext siehe auch: Marie-Luise Heckmann, "Herzog Albrecht und die Reformation in Preußen - im Spiegel von Selbstzeugnissen," Preußenland N.F. 9 (2018): 59-88.

79 Vgl. Herrmann, Der Deutsche Orden, 83-1 32.

8o Über die Wichtigkeit der Türkenfrage: Winfried Schulze, Reich und Türkengefahr im späten I 6 . Jahrbundert. Studien zu den politischen und gesellschaftlichen Auswirkungen einer äußeren Bedrohung (München: Beck, 1978). Über Herzog Albrechts Beziehungen zu den Reichsständen 
missvorschläge der Reichsstände scheiterten vor allem an der Unnachgiebigkeit des Administrators und seines Umkreises. Das Thema Preußen wurde von einem Reichstag zum nächsten verschoben und dabei die Acht regelmäßig suspendiert. ${ }^{{ }^{8}}$

Die Kommunikation zwischen den Ordenszweigen beschäftigte sich oft mit der preußischen Frage. ${ }^{82}$ Jedoch hatte dieses Thema für die Livländer keine Priorität. Einige livländische Ordensleute waren zwar um i 530 der Meinung, dass Preußen besser an den livländischen Meister hätte verlehnt werden sollen, weil man dadurch das Land zum Orden zurückbringen könne; aber solche Äußerungen scheinen eher Ausdruck der Enttäuschung über die Niederlage im Wettbewerb um die Hochmeisterstelle gewesen zu sein. ${ }^{83}$ Jedenfalls scheinen die livländischen Gesandten auf den Reichstagen zur preußische Frage nicht das Wort ergriffen zu haben, abgesehen von Philipp von der Brüggen, der recht enge Beziehungen zum

und seine Türkenhilfe: Antjekathrin Graßmann, Preußen und Habsburg im I6. Jabrhundert, Studien zur Geschichte Preußens is (Köln-Berlin: Grote'sche Verlagsbuchhandlung, 1968), 74-I 19; Herrmann, Der Deutsche Orden, 101-103, I26; Die Türkensteuer im Herzogthum Preußen I540, Bd. I, Fischhausen - Schaaken - Neuhausen - Labiau, hrsg. v. Hans H. Diehlmann (Hamburg: Verein für Familienforschung in Ost- und Westpreußen, I998); Bd. 2, Memel - Tilsit, hrsg. v. Hans H. Diehlmann (Hamburg: Verein für Familienforschung in Ostund Westpreußen, 2006); Bd. 3, Ragnit, Insterburg, Georgenburg und Saalau, hrsg. v. Hans H. Diehlmann (Hamburg: Verein f. Familienforschung in Ost- u. Westpreußen, 2008). Über die Erörtungen dieser Frage auf den Reichstagen von 1532 bis I 555 siehe: Der Reichstag in Regensburg, hrsg. v. Aulinger, 332-333, 356, 358, 730-736, 774-776, 848-849; Der Reichstag zu Regensburg I54I, hrsg. v. Lutterberger und Neerfeld, I 583-1704; Der Reichstag zu Speyer I 542, hrsg. v. Schweinzer-Burian, 4 I 5 , I I I 3 - I I I 5; Der Reichstag zu Nürnberg I542, hrsg. v. Schweinzer-Burian, 298, 378, 379, 389-391, 424, 477-478, 493, 530, 780, 783, 859-864; Der Speyrer Reichstag von 1544, hrsg. v. Eltz, 577-578, 595-596, 603-604, 606-607, 61 4, 622-623, 708, 7 I I , 7 1 9, 730, 784, 2 I 34-2 I 40; Der Reichstag zu Worms I545, hrsg. v. Aulinger, 57, 81, 796, 1 560-1 568, 1648; Der Reichstag zu Regensburg 1546, I 55, 223, 493; Der Reichstag zu Augsburg 1547/48, hrsg. v. Machoczek, 2576-2597; Der Reichstag zu Augsburg I550/5I, hrsg. v. Erwein Eltz, Deutsche Reichstagsakten. Jüngere Reihe: Deutsche Reichstagsakten unter Kaiser Karl V. I9 (München: Oldenbourg, 2005), I 374, I 4 I 7-I 41 9, I 457-I 460; Der Reichstag zu Augsburg I55s, hrsg. v. Aulinger, Eltz, und Machoczek, 2444. Über das Verhalten des deutschen Zweiges vgl. Herrmann, Der Deutsche Orden, 83-1 32; Udo Arnold, "Mergentheim und Königsberg/Berlin - die Rekuperationsbemühungen des Deutschen Ordens auf Preußen," Württembergisch Franken 60 (1 976): 1 4-54.

82 Dieses Thema tauchte oft in der Kommunikation zwischen den Meistern auf, besonders während der $1520 e r$ Jahre, vgl. Nordosteuropa, hrsg. v. Wieser, 42-91, aber auch später, vor allem während der Reichstage: ebd., 92, 97-99, I I I-I I 2, I I I, I 53, I 62, I65, I68-I69, I 84 Nrn. 696, 736, 747-748, 76 I, 872, 877-879, I 245-I 246, I 259, I 348, I 373, I 403-I 404, I 542; Der Reichstag zu Speyer 1542, hrsg. v. Schweinzer-Burian, I I I 3 - I I 5 ; Der Reichstag zu Nürnberg I542, hrsg. v. Schweinzer-Burian, 862, 864; Der Reichstag zu Worms 1545, hrsg. v. Aulinger, I640.

83 Vgl. Graßmann, Preußen und Habsburg, 46. 
Administrator Wolfgang Schutzbar ( I 543-I 566) pflegte. ${ }^{84}$ Während der Reichstage zu Augsburg von I 547/1 548 und I 550/1 55 I wirkte Brüggen im Auftrag sowohl des livländischen Meisters als auch des Administrators ${ }^{85}$ und hielt zumindest einen Vortrag bezüglich Preußens. ${ }^{86}$ In diesem Fall kann man Brüggen allerdings eher als einen Vertreter des Administrators betrachten, und Schutzbar musste Brüggens langen Aufenthalt im Reich vor dem livländischen Meister sogar entschuldigen ${ }^{87}$ Zudem konnte bei Brüggens Aktivitäten die Tatsache mitspielen, dass der Kaiser den Schmalkaldischen Krieg ( I 546- I 547) gegen Herzog Albrechts protestantische Unterstützer gewonnen hatte. Deshalb brauchten die Livländer zumindest im Reich weniger Rücksicht auf den preußischen Herzog zu nehmen als sonst. ${ }^{88}$

Somit kann man im Allgemeinem sagen, dass der livländische Zweig sich normalerweise nicht aktiv mit der Rekuperationsfrage beschäftigte. Stattdessen hat der Administrator Livland in seiner Rhetorik benutzt, um die Wiedererlangung Preußens zu begründen. ${ }^{89}$ Wie der Deutschmeister schon 1526 betonte der Administrator auch auf den späteren Reichstagen oft, dass sowohl der Deutschmeister als auch der livländische Meister keine Verantwortung für die Säkularisation Preußens trügen und dass auch der Letztere die Rückgewinnung unterstütze. ${ }^{\circ} \mathrm{Zudem}$ wurde oft hinzugefügt, dass Livland wegen Preußens Abfall vom Reich abge-

${ }_{84}$ Vgl. Nordosteuropa, hrsg. v. Wieser, I 72, I75, I79, I 8 I-I 83, I 87, I 89-1 90, I 92, I 95 Nr. I 432 , I 438, I 463, I 50 I, I 522, I 524, I 533, I 57 I, I 592, I 594, I6I 3, I 638. Über Brüggen siehe auch: Theodor Schiemann, "Landleben in Kurland im 16. Jahrhundert," Characterköpfe und Sittenbilder aus der baltischen Geschichte des sechszehnten Jahrhunderts (Mitau: E. Behre, I 877), I 3 I-I 38, I 46-I 5 I; Genealogisches Handbuch der baltischen Ritterschaften, Tl. 3, Kurland, Bd. I, hrsg. v. Verband des kurländischen Stammadels, bearb. v. Oskar Stavenhagen (Görlitz: Verlag für Sippenforschung und Wappenkunde C. A. Starke, I937-1939), I 8-19, 2 I.

85 Nordosteuropa, hrsg. v. Wieser, I75, I79, I 84-I 86 Nr. I 462, I 463, I 50 I, I 542, I 552 , I 553 , I56I-I563.

86 Ebd., 178 Nr. 1489 .

87 Ebd., I75 Nr. I 466. Der livländische Meister war auch damit unzufrieden, dass Brüggen ihn nicht informiert hatte (ebd., I 82 Nr. I 526 ), und der Administrator musste Brüggens Verhalten auch vor dem Komtur von Goldingen rechtfertigen (ebd., i 83 Nr. I 535 ).

88 Über die Lage in Livland nach dem Schmalkaldischen Krieg: Juhan Kreem, "Das Augsburger Interim in Livland. Evangelische und Altgläubige in den baltischen Landen in der Mitte des 16. Jahrhunderts," Historisches Jahrbuch I 34 (20 I 4): I 2 I - I 4 I.

89 Manchmal behaupteten jedoch Herzog Albrechts Unterstützer, dass sowohl der Deutschmeister als auch der livländische Meister gegen Herzog Albrecht agitierten, aber das wurde nicht näher präzisiert (z.B. Der Reichstag zu Regensburg I546, hrsg. v. Aulinger, I 54-I 55). Damit waren wohl die Erörterungen zwischen den Ordensleuten außerhalb der Reichstage gemeint.

90 Der Reichstag in Regensburg, hrsg. v. Aulinger, 735-736; Der Reichstag zu Regensburg I54I, hrsg. v. Lutterberger und Neerfeld, 1652-1653; Der Speyrer Reichstag von 1544, hrsg. v. Eltz, 2 1 35-2 I 38; Der Reichstag zu Augsburg 1547/48, hrsg. v. Machoczek, 2587-2588. 
schnitten sei und somit das Land durch die Russen wesentlich stärker gefährdet sei; außerdem wurde an die früheren, tapferen Kämpfe der Meister gegen die Feinde der Christenheit erinnert. ${ }^{91}$

Vor allem war es die politische Lage Livlands, die es dem lokalen Ordenszweig nicht erlaubte, sich auf einen offenen Konflikt mit Herzog Albrecht einzulassen. Hinter dem Herzog standen seine mächtigen Verwandten, vor allem der König von Polen, und zudem sollte man nicht vergessen, dass der Landweg von Livland nach Deutschland durch Preußen führte und der livländische Zweig ihn auch nach der Säkularisation benutzen wollte. Außerdem konnte der Herzog sogar ein potenzieller Bündnispartner vor allem gegen Russland sein. Deshalb beabsichtigte der livländische Zweig normalerweise, trotz gegenseitiger Befürchtungen von Angriffen, mit dem Herzog gutnachbarliche Beziehungen zu unterhalten. Allerdings waren die Beziehungen zwischen Herzog Albrecht und dem livländischen Ordenszweig kompliziert, weil es in Livland eine einflussreiche preußische Partei gab, deren wichtigstes Mitglied der Bruder des Herzogs war: Markgraf Wilhelm, zuerst Koadjutor (1 529-1 539) und danach Erzbischof von Riga (I 539-1 563).92

Wilhelms Ankunft in Livland intensivierte den jahrhundertelangen Kampf des Ordens mit dem Erzbischof um die Vormachtstellung. Die Lage wurde besonders kompliziert wegen des Konflikts um die Stadt Riga, über die der Orden und der Erzbischof eine Mitherrschaft hatten. I 525 hatten die Rigaer aufgrund der Reformation den Erzbischof als Mitregent verweigert, und um die Einmischung des preußischen Herzogs zu vermeiden, musste der Orden die Alleinherrschaft akzeptieren. Dies löste einen langgezogenen Streit aus, der erst I 55 I nach mühsamen Verhandlungen beendet werden konnte. ${ }^{93}$ Während dieses Konflikts stellte der

${ }_{91}$ Z.B. Der Reichstag zu Regensburg I54I, hrsg. v. Lutterberger und Neerfeld, 1646, I691; Der Reichstag zu Augsburg I550/5I, hrsg. v. Eltz, I 457-1 458.

92 Über die politische Lage in Livland und Markgraf Wilhelm: Paul Karge, "Die Berufung des Markgrafen Wilhelm zum Koadjutor des Rigaschen Erzbichofs: ein Beitrag zur Reformationsgeschichte," Baltische Monatsschrift 61 (1906): I17-156; Hans Quednau, Livland im politischen Wollen Herzog Albrechts von Preußen: ein Beitrag zur Geschichte des Herzogtums Preußen und des preußisch-livländischen Verbältnisses 1525-1540, Deutschland und der Osten. Quellen und Forschungen zur Geschichte ihrer Beziehungen I 2 (Leipzig: Hirzel, 1939); Thomas Lange, Zwischen Reformation und Untergang Alt-Livlands. Der Rigaer Erzbischof Wilhelm von Brandenburg im Beziehungsgeflecht der livländischen Konföderation und ihrer Nachbarländer, Hamburger Beiträge zur Geschichte des östlichen Europa 2 I (Hamburg: Kovač, 20 I 4); Madis Maasing, The Role of the Bishops in the Livonian Political System (in the First Half of the I 6 th Century), Dissertationes Historiae Universitatis Tartuensis 37 (Tartu: Tartu Ülikooli kirjastus, 2016).

93 Constantin Mettig, Geschichte der Stadt Riga (Riga: Jonck \& Poliewski, I 897), 173-203, 220-237; Thomas Lange, "Zwischen Unterwerfung und Konfrontation. Die Reformation in Riga im Spannungsfeld zwischen der Stadt und ihren Herren," in Preußen und Livland im Zeichen 
Kaiser dem Erzbischof einige Mandate gegen den Orden und die Stadt aus. Daraufhin verteidigte sich der livländische Meister auf dem Reichstag von I 530 und ergriff auch gegen Koadjutor Wilhelm das Wort. ${ }^{94}$ Der Meister erhielt in dieser Sache auch Unterstützung durch den Administrator, der auf dem gleichen Reichstag über den Plan des preußischen Herzogs sprach, mit Hilfe seines Bruders Livland Polen zu unterstellen.95 Auch danach tauchte die Rigaer Problematik recht oft in der Korrespondenz des Administrators auf. ${ }^{96}$ Besonders deutlich wurde das I 539-I 540, als Wilhelm Erzbischof wurde und der livländische Meister mit dem Administrator kooperierte, um die Interessen des Ordens gegen ihn zu schützen und Wilhelm zu zwingen, als ein Priesterbruder auch in den Orden einzutreten daraus wurde jedoch nichts. ${ }^{97}$ Auf den Reichstagen der $1540 e r$ Jahre wurde der Konflikt um Riga manchmal erwähnt, wenn der Erzbischof und seine Parteigänger aus Riga gegen den Orden Beschwerden erhoben, aber der livländische Zweig konnte seine Kontakte mit dem deutschen Zweig ausnutzen und überzeugendere Gegenberichte vortragen..$^{8}$

Die Spannungen mit Erzbischof Wilhelm spitzten sich während der Koadjutorfehde (1556-I 557) zu, als der Erzbischof gegen den Willen des Ordens und anderer Bischöfe, aber mit Unterstützung der Herzöge von Preußen und Mecklenburg sowie des Königs von Polen, Herzog Christoph von Mecklenburg als seinen Koadjutor annahm. Danach scheiterten aber die Kompromissverhandlungen, der Orden eroberte das Erzbistum Riga und verhaftete den Erzbischof.99 Darüber äu-

der Reformation, hrsg. v. Arno Mentzel-Reuters und Klaus Neitmann, Tagungsberichte der Historischen Kommission für ost- und westpreußische Landesforschung 28 (Osnabrück: Fibre, 20 I 4), 2 I I-240; Ulrich Müller, "Erzbischof Wilhelm von Riga und die Reformation in Livland I 535-1 563," in ebd., 263-266, 272-278, 308-322.

94 Nordosteuropa, hrsg. v. Wieser, 94 Nr. 71 15, 98 Nr. 752.

95 Ebd., 94 Nr. 7 1 8, 99 Nr. 755.

96 Vgl. ebd., 79 Nr. 589 ; 85 Nrn. 632-633; 86 Nrn. 641, 643; 88 Nrn. 65 8, 66 I ; 89 Nrn. 662-664, 668-669; 91 Nrn. 684-68 5, 688-689; 94 Nrn. 71 1 , 71 1 4; 95 Nr. 722 ; 96 Nr. 730; 100 Nr. 764 ; I о I Nr. 77 I, 775; 107 Nr. 830; I 20, Nr. 955; I 25, Nrn. 998, 999; 133 Nr. I070-I 07 I.

97 Ebd., I 33 Nr. I072; I 42 Nrn. I I 66- I I67; I 43 Nr. I 170, I 172, I I 74- I I 77; I 44 Nrn. I I 83 - I 1 88; I 45 Nrn. I 193-I 194, I 196-I I 97; 146 Nr. I 200. Nach der sog. Bulla habitus sollten alle Rigaer Erzbischöfe und Domherren Mitglieder des Ordens sein, vgl. Akten und Rezesse der livländischen Ständetage, Bd. I, 5 . Lief., (1450-I454), hrsg. v. Leonid Arbusow, jun. (Riga: Jonck \& Poliewsky, I 929), 504-5 1 3 Nr. 537. Zu Wilhelms Gegenmaßnahme: Lange, Zwischen Reformation, I $42-146$.

${ }_{98}$ Der Speyrer Reichstag von 1544 , hrsg. v. Eltz, 913 ; Der Reichstag zu Worms 1545, hrsg. v. Aulinger, I 61 I-I 161 3, I 623, I 648, I 693; Nordosteuropa, hrsg. v. Wieser, I 67 Nr. I 387.

99 Alexander Bergengrün, Herzog Christoph von Mecklenburg, letzter Koadjutor des Erzbistums Riga: ein Beitrag zur livländischen und mecklenburgischen Geschichte (Reval: Kluge, 1898), 20-94; Lange, Zwischen Reformation, 161-242; Stefan Hartmann, "Neue Quellen zur livländischen Koadjutorfehde 1 555/6," in Aus der Geschichte Alt-Livlands: Festschrift für Heinz 
Berte sich auf dem Reichstag von Regensburg (1 556/ I 557) zuerst der Kurfürst von Brandenburg, ein Verwandter des Erzbischofs, und beschuldigte den livländischen Zweig des Landfriedensbruchs. ${ }^{100}$ Zunächst fanden diese Anschuldigungen auch Gehör, weil die livländischen Gesandten noch nicht anwesend waren. Sie waren nämlich erst nach Mergentheim gereist und hatten den Administrator um Hilfe gebeten. Außerdem schlugen die Livländer vor, den günstigen Moment auszunutzen, um Preußen von Wilhelms Bruder zurückzuerobern. ${ }^{101}$ Der Administrator hatte aber keine Möglichkeit, die Livländer mit Kriegsleuten zu unterstützen, geschweige denn einen Kriegszug gegen Preußen zu organisieren. Deshalb schlug er den Gesandten vor, die Sache auf den Reichstag zu bringen. Zusätzlich bat er noch König Ferdinand I. ( 153 I - I 564 , Kaiser seit I 558 ) um Unterstützung. ${ }^{102}$

Der Gegenbericht der Livländer, den sie einen Monat nach den Anschuldigungen des Kurfürsten präsentierten, und die Dispute mit den mecklenburgischen Gesandten brachten die Meinungen auf dem Reichstag ins Gleichgewicht; ${ }^{103}$ einige Reichsstände äußerten sogar Unterstützung für den Orden. ${ }^{104}$ Nach längeren Verhandlungen entschieden die Reichsstände und König Ferdinand schließlich, eine Reichsgesandtschaft als Vermittler nach Livland zu schicken. ${ }^{105}$ Gleichzeitig plante auch der deutsche Zweig, eine Gesandtschaft nach Livland zu senden, aber im Sommer 1557 rief der Administrator die Ordensgesandten zurück, bevor sie von Lübeck nach Livland segeln konnten. ${ }^{106}$ Deswegen fand die Vermittlung zwischen den Livländern und dem polnischen König ohne die direkte Teilnahme des deutschen Zweiges statt.

von zur Müblen zum go. Geburtstag, hrsg. v. Klaus Militzer und Bernhart Jähnig, Schriften der Baltischen Historischen Kommission I 2 (Münster: Lit, 2004), 275-306; Madis Maasing und Dmitry Weber, "Die Gerüchte über den Tod des Erzbischofs Wilhelm von Riga im Sommer I 556," Acta Historica Tallinnensia 25 (2019): 3- 18.

100 Reichstag von Regensburg 1556/57, hrsg. v. Leeb, I $270-$ I 272 Nr. 5 I I.

${ }^{\text {1о }}$ Dies schlugen sowohl der Koadjutor des livländischen Meisters Wilhelm von Fürstenberg (Nordosteuropa, hrsg. v. Wieser, 2 I 6 Nr. I 830) als auch der Gesandte Georg von Syburg zu Wischlingen vor (Reichstag von Regensburg I556/57, hrsg. v. Leeb, I 273).

${ }_{102}$ Reichstag von Regensburg I556/57, hrsg. v. Leeb, I 273. Vgl. auch Nordosteuropa, hrsg. v. Wieser, 2 I 4-2 I 6 Nrn. I 8 I 3, I 817 , I 82 I, I 826.

${ }_{103}$ Reichstag von Regensburg I556/57, hrsg. v. Leeb, I 272 - I 280, I 28 I- I 285.

${ }^{104}$ Beispielsweise hatten die pommerschen Gesandten den livländischen Zweig als ein bedeutsames Glied des Reichs beschrieben und dessen Erhaltung als hochwichtig betont, vgl. ebd., I 280-I 28 I .

105 Ebd., I 286-1 295 .

${ }^{106}$ Nordosteuropa, hrsg. v. Wieser, 224 Nr. 1907 ; Die Urkunden des Deutschordenszentralarchivs in Wien: Regesten, Tlbd. IV, Januar I527 - April I597, hrsg. v. Marian Tumler und Udo Arnold, Quellen und Studien zur Geschichte des Deutschen Ordens 60/IV (Weimar: VDG, 2019), 1 596-I 597 Nr. 5656. 


\section{Besteuerung, Reichsstandschaft, Russen und TÜRKen}

Zusätzlich zu den genannten Problemen tauchte noch ein für den Orden wichtiger Problemkreis auf den Reichstagen auf - die Reichssteuer, die mit der Türken- und Russengefahr, aber auch mit der Reichsstandschaft verbunden war. Für den Administrator war insbesondere die Bezahlung der Türkensteuer entscheidend, weil sie enge Beziehungen zur Reichszentrale ermöglichte, besonders zum kaiserlichen Haus; auch zeigte sie, dass der Orden seine frühere Aufgabe, den Kampf gegen die Glaubensfeinde, nicht aufgegeben hatte. ${ }^{107}$ Teilweise hatte der Orden damit sogar Erfolg, weil der Administrator auf den Reichstagen sich im näheren Umkreis des Kaisers bewegte und auch einige Reichsämter bekleidete. ${ }^{108}$ Jedoch funktionierte diese Strategie in Bezug auf Preußen nicht, weil auch der Herzog, wie schon gesagt, Türkenhilfe leistete. Außerdem begannen mehrere Fürsten und Reichsstädte seit den I $520 e r$ Jahren, die Ordensgüter ihrer Territorialherrschaft zu unterstellen, was u. a. bedeutete, dass sie sich das Recht nahmen, in diesen Ordensgebieten Reichssteuern einzuziehen. Diese Frage war von grundsätzlicher Bedeutung, weil der Administrator durch die Besteuerung seine Reichsfürstenrechte demonstrieren und den schlechten finanziellen Zustand des Ordenszweiges verbessern konnte. ${ }^{109}$ Die größten Probleme hatte der Orden wahrscheinlich mit dem Landgrafen Philipp von Hessen (1508-1567), der sowohl den Herzog von Preußen unterstützte als auch den Landkomtur von Marburg stark bedrängte. ${ }^{10}$ Auf den Reichstagen versuchte der Administrator, seine Reichsfürstenstellung auszunutzen, und behauptete, dass alle Ordensbesitzungen im Reich ihm unterstellt und

107 Herrmann, Der Deutsche Orden, 84, 87-88, 1 57, 259; Hofmann, Der Staat des Deutschmeisters, I 87-I88, I 95-I98, 207-2I 2.

${ }_{108}$ Besonders beim Reichstag von Regensburg (154I) weilte der Administrator im Umkreis des Kaisers (Der Reichstag von Regensburg IS4I, hrsg. v. Lutterberger und Neerfeld, 624-625, 639-640, 732-733, 740, 745-747, 2937); zudem fungierte er als kaiserlicher Kommissar (ebd., I 284, 2867) und wurde als Visitator des Reichskammergerichts genannt (ebd., 3573, 36 I 3 ; Der Reichstag von Nürnberg I542, hrsg. v. Schweinzer-Burian, 7 I ). Außerdem wurde der spätere Administrator Schutzbar Reichspfennigmeister, der die Türkensteuer einzog (Herrmann, Der Deutsche Orden, I 7 I-172). Schließlich wurden sowohl Cronberg als auch Schutzbar auf den Reichstagen ( 1530 bzw. I 543 ) feierlich mit den preußischen Regalien belehnt.

109 Besonders die Besitzungen in den mitteldeutschen Balleien Hessen (Marburg), Sachsen und Thüringen waren Druck ausgesetzt, weil die Balleien Österreich, Etsch, Biesen und Utrecht unter starken Einfluss der Dynastie Habsburg gerieten (Herrmann, Der Deutsche Orden, I 57- I 88, 198-204, 25 I-254).

${ }_{1} \circ$ Katharina Schaal, Das Deutschordenshaus Marburg in der Reformationszeit. Der Säkularisationsversuch und die Inventare von 1543, Untersuchungen und Materialien zur Verfassungs- und Landesgeschichte is (Marburg: Elwert, 1996); Herrmann, Der Deutsche Orden, 164-174; Hofmann, Der Staat des Deutschmeisters, 206-207, 2 I I. 
damit reichsunmittelbar seien, doch konnten die Verhandlungen nicht zu einem für den Orden günstigen Ergebnis geführt werden. ${ }^{111}$ Das bedeutete, dass die allgemeine Reichssteuer in den meisten Ordensgebieten von den lokalen Territorialherren eingezogen wurde; nur im Deutschmeistertum und in Franken konnte der Administrator sein Besteuerungsrecht durchsetzen. ${ }^{12}$

Im Gegensatz zum deutschen Ordenszweig hatte der livländische Zweig nie Türkensteuer bezahlt und hatte sich immer bemüht, sich so wenig wie möglich mit den Reichssteuern zu beschäftigen. ${ }^{113}$ Bei der Erlangung der Reichsregalien ( I 525-I 526) hatten die Gesandten des livländischen Meisters sogar versucht, alle Reichsforderungen aufgrund der russischen Gefahr für immer aufzuheben, und sie wiederholten diesen Versuch auf dem Reichstag von I $530 .{ }^{114}$ Später nutzten die Livländer das Russland-Argument, um die Leistung der Türkenhilfe zu vermeiden, indem sie die russische Gefahr mit der türkischen gleichsetzten. ${ }^{15}$

Die einzige Reichsabgabe, die der livländische Zweig seit den I 53 oer Jahren regelmäßig bezahlte, war für das Reichskammergericht bestimmt. Aber auch damit hatten die Livländer zuerst einige Probleme: Bis zum Beginn der I $540 e r$ Jahre be-

${ }^{11}$ Der Orden hatte mit der Stadt Nürnberg sowohl auf dem Reichstag (Deutsche Reichstagsakten unter Kaiser Karl V., 7, hrsg. v. Kühn, 477-478) als auch auf den Versammlungen der mittelund süddeutsche Stände (ebd., I05-106, I I 3, I I 7, I 56-157, 249, 25 I, 416, 433, 459, 456, 466, I007, 1030, 1079, I 109-I I 10). Auch mit anderen Reichsstädten hatte der Orden Probleme (Deutsche Reichstagsakten unter Kaiser Karl V., Bd. 8, hrsg. v. Wolfgang Steglich, Deutsche Reichstagsakten. Jüngere Reihe: Deutsche Reichstagsakten unter Kaiser Karl V. 8 (Göttingen: Vandenhoeck und Ruprecht, I970/1971), 450-45 I, 759, 78 I). Auf dem Reichstag von I 54 I kam es zum Streit zwischen dem Orden und Frankfurt (Der Reichstag zu Regensburg I54I, hrsg. v. Lutterberger und Neerfeld, 2610, 2792-2793, 3275). Zu Problemen mit Hessen: Deutsche Reichstagsakten unter Kaiser Karl V., 7, hrsg. v. Kühn, 761, 983; Der Reichstag in Regensburg, hrsg. v. Aulinger, I 87, 692, 702-703.

112 Vgl. Hofmann, Der Staat des Deutschmeisters, 207-220; Herrmann, Der Deutsche Orden, I 48, I 68-169, 203-204, 220-224, 245-248.

${ }_{113}$ Zum I 5. Jahrhundert: Mihkel Mäesalu, "Die Steuerforderungen des Heiligen Römischen Reiches an die Kirchenprovinz Riga im I 5. Jahrhundert," in Livland - eine Region am Ende der Welt?, hrsg. v. Selart und Thumser, 259-282.

${ }^{114}$ Deutsche Reichstagsakten unter Kaiser Karl V., 7, hrsg. v. Kühn, 50; Nordosteuropa, hrsg. v. Wieser, I00-Io I Nr. 770.

is Vgl. Anti Selart, "Political Rhetoric and the Edges of Christianity: Livonia and Its Evil Enemies in the Fifteenth Century," in The Edges of the Medieval World, hrsg. v. Juhan Kreem und Gerhard Jaritz, CEU Medievalia I I (Budapest: Central European University, 2009), 55-69; Madis Maasing, "Infidel Turks and Schismatic Russians in Late Medieval Livonia," in Fear and Loathing in the North, hrsg. v. Cordelia Heß und Jonathan Adams (Berlin-München-Boston: de Gruyter, 20 I 5), 347-388; Maasing, "Livland und die Reichstage," 300-303. 
nötigten sie dafür immer die Beihilfe des deutschen Zweiges. ${ }^{116}$ Die livländischen Bischöfe bezahlten das Geld für das Reichskammergericht sehr unregelmäßig. Das war wohl eine der Ursachen, warum die Reichstagsteilnehmer die Reichszugehörigkeit Livlands während der I $540 e r$ Jahre in Zweifel zogen. ${ }^{17}$ Nach langen Verhandlungen wurde die Besteuerung Livlands endlich auf dem sog. Geharnischten Reichstag von Augsburg (1 547/ i 548) geregelt: alle livländischen Herrscher sollten eine ermäßigte Abgabe für das Reichskammergericht zahlen, von allen anderen Reichssteuern wurden sie befreit, solange die Russengefahr anhielt. Auf diese Weise wurden die livländischen Herrscher ausdrücklich als vollständige Reichsglieder akzeptiert. ${ }^{118}$ Auf den ersten Blick erscheint diese Lösung für die Livländer ziemlich günstig, aber schon auf dem nächsten Reichstag (I 550/I 55 I) kam ihre negative Seite zum Vorschein. Die offensive Politik Ivans IV. (I 533 - I 584 ) hatte die Livländer sehr beunruhigt. Deshalb suchten sie Hilfe bei den Reichsständen, aber diese erklärten, dass sie Livland schon durch die Steuerbefreiung geholfen hätten. ${ }^{19}$ Bis zum Beginn des Livländischen Krieges wurde auf den Reichstagen die Livlandhilfe nicht mehr erörtert. Auch der deutsche Zweig schlug dieses Thema nicht vor; außerhalb der Diskussion um Preußen erwähnte er die Russengefahr bis zum Beginn des Livländischen Kriegs fast nie. ${ }^{120}$

${ }_{116}$ Anfangs hatte der deutsche Zweig das Geld ausgelegt, und die Livländer hatten es erst Jahre später erstattet. Später entrichteten sie die Abgabe auch direkt. Vgl. Demel, "Zur Reichspolitik," I 60, I 62; Nordosteuropa, hrsg. v. Wieser, xxx, Nrn. 838, 854, 936, I000-100 I, I003-1004, I030, I I I 5, I I 4 I, I I 89-I I 90, I 250, I 308.

117 Vgl. Maasing, "Livland und die Reichstage," 306-307.

${ }_{118}$ Der Reichstag zu Augsburg I547/48, hrsg. v. Machoczek, 656, 66 I, 674, 698, 726, 728, 906, I 483, I 5 I 4, I 608, I 640-164I, 2355-236I, 2365-2366, 24I0-24II , 2422-2423, 2429-2430, 2643-2644. Zu den Verhandlungen auf anderen Reichstagen über die russische Gefahr und die Besteuerung: Maasing, "Livland und die Reichstage," 295-303.

$119 \mathrm{Vgl}$. Madis Maasing, "Livonia and depictions of Russians at Imperial Assemblies before the Livonian War", Studia Slavica et Balcanica Petropolitana [im Druck].

${ }_{120}$ Nur auf dem Reichstag von I 532 hatte der Administrator die Russen als Verbündete der Türken genannt, die angeblich einen Angriff auf Polen, Mähren und Schlesien planten (Der Reichstag in Regensburg, hrsg. v. Aulinger, 965 Nr. 253). Außerdem hatte der Administrator Livland gegen die Aktivitäten von Hans Schlitte unterstützt, aber das fand neben den Reichstagen statt (Nordosteuropa, hrsg. v. Wieser, I 98 Nr. 1667, $201-203$ Nrn. 1688, I692, I 699, 1705, I 709- I 7 I o; Bernhard Diestelkamp, "Eine versuchte Annäherung Zar Iwans IV., des Schrecklichen, an den Westen? Ein Reichskammergerichtsprozeß, der dies nahelegt", in Reich, Regionen und Europa in Mittelalter und Neuzeit. Festschrift für Peter Moraw, hrsg. v. Paul-Joachim Heinig, Sigrid Jahns, Hans-Joachim Schmidt, Rainer Christoph Schwinges, und Sabine Wefers, Historische Forschungen 67 (Berlin: Duncker \& Humblot, 2000), 305-322). Über die Tätigkeit des deutschen Zweiges nach Ausbruch des Krieges und über die Reichstagsverhandlungen zu Livland: Demel, "Die Rekuperationsbemühungen;" Manfred Hellmann, "Gesandte des Deutschen Ordens am Hofe Ivans IV. (I 564)," in Russland und Deutschland: Aufsätze, hrsg. v. Uwe 


\section{Abschliessende Betrachtungen}

Die Säkularisation Preußens änderte die Beziehungen zwischen dem livländischen Ordenszweig und dem deutschen Zweig grundsätzlich. Nach einer kurzen Konkurrenzperiode um die Hochmeisterwürde wurde der Deutschmeister das neue Ordensoberhaupt. Schon aus diesem Grund musste der livländische Meister sich um ein enges Verhältnis zu ihm bemühen; außerdem wurden die Verbindungen zwischen Livland und den zentralen Reichsstrukturen immer wichtiger. Dabei übernahm der Administrator größtenteils die Vermittlerrolle, die früher der Hochmeister ausgefüllt hatte, besonders in den Beziehungen mit dem Kaiser. Es gab jedoch einen bemerkenswerten Unterschied: früher hatten die Gesandten des Hochmeisters die livländischen Angelegenheiten im Reich vorgetragen, aber nach I 525 schickten die Livländer normalerweise ihre eigenen Gesandtschaften, die zuerst in Mergentheim vorsprachen und danach entweder weiter zum Kaiser oder zu den Reichstagen zogen.

Im Allgemeinen scheint es üblich gewesen zu sein, dass beide Zweige ihre Probleme auf den Reichstagen selbständig und ohne offizielle Mitwirkung des anderen präsentierten. Allerdings konnte man einander bei den wichtigsten Problemfeldern sowohl unterstützen als auch ausnutzen. Der deutsche Zweig konnte in der Rekuperationsfrage Livland als ein vom Herzog von Preußen gefährdetes Reichsglied darstellen, das zudem als Vormauer der Christenheit von den ungläubigen Russen stets bedroht sei und im Prinzip die Politik des Administrators unterstütze. Die Livländer dagegen konnten den deutschen Zweig in den Streit um das Erzbistum Riga einbeziehen, weil dieses Problem durch die Person des Markgrafen Wilhelm direkt mit Preußen verbunden war. Außerdem war der Administrator wahrscheinlich leicht zu überzeugen, dass die Rekuperationsfrage befördert werde, wenn die Ambitionen der Brüder Albrecht und Wilhelm in Livland eingedämmt würden.

Bei den Reichssteuern und den damit verbundenen Fragen der Reichsstandschaft waren die gemeinsamen Interessen weit geringer. Völlig gegensätzlich waren die Ansichten zur Türkensteuer: während die Bezahlung der Türkenhilfe für den Administrator sehr wichtig war, wollten die Livländer die Entrichtung aller Reichssteuern so weit wie möglich vermeiden und begründeten das mit einer Rhetorik, die die Russen mit den Türken gleichsetzte. Die einzige Ausnahme, bei der die Zweige kooperierten, scheint die Bezahlung des livländischen Reichkammerge-

Liszkowski, Kieler Historische Studien 22 (Stuttgart: Klett, I 974), 38-50; Anti Selart, “Иван Грозный, Кайзер Аивонский? К истории возникновения идеи о российского вассального государства в Аивонии", Studia Slavica et Balcanica Petropolitana 2 (20 I3), I 80- 197. 
richtsgeldes gewesen zu sein, in der die Livländer vielleicht eine Minimalbedingung für die Reichsstandschaft sahen. Auf den Reichstagen beschäftigte sich aber keiner der beiden Zweige mit den Besteuerungs- oder Reichsstandschaftsproblemen des anderen.

Ein recht wichtiger Grund, warum der Administrator den livländischen Meister fast nie offiziell auf den Reichstagen vertrat und auch dort nicht mit dessen Problemen beschäftigt sein konnte, war wohl, dass der livländische Zweig sich als völlig selbständiger Reichsstand präsentieren wollte, der reichsrechtlich nicht von dem deutschen Zweig abhängig sei, um damit sowohl seine Reputation zu erhöhen als auch seinen politischen Spielraum zu erweitern. Das gleiche Ziel hatte der Deutschmeister selbst gehabt, als er I 524 in den Sessionstreit mit dem Hochmeister geriet. Obwohl es zwischen den deutschen und livländischen Zweigen nicht so scharfe Gegensätze gab, ist trotzdem klar, dass ihre politischen Ziele recht oft unterschiedlich waren und dass sie vielleicht gerade deswegen gemeinsame Reichstagsgesandtschaften vermeiden wollten, um eher als selbständige Mächte auftreten zu können. Das einzige Mal, dass der Administrator den livländischen Meister vertrat (in Regensburg, I 546), diskutierte man keine für Livland wichtigen Themen. Diese Grundhaltung schloss Zusammenarbeit auf den Reichstagen in keiner Weise aus, aber sie geschah eher inoffiziell und hat deswegen nicht viele Spuren in der offiziellen Reichstagsdokumentation hinterlassen.

Auf jeden Fall scheint die Bilanz der Beziehungen eher einseitig zu sein: es waren fast immer die Livländer, die von dem deutschen Zweig Hilfe erhielten, während die Probleme des Letzteren oft ohne zufriedenstellende livländische Antwort blieben. Das verursachte auch Frustrationen im deutschen Zweig. Die Meinung Wolfgang von Schutzbars, dass der deutsche Zweig eigentlich mehr Hilfe aus Livland brauche als umgekehrt, ${ }^{121}$ hätten wahrscheinlich mehrere Ordensleute in Deutschland geteilt. Allerdings war diese Art der Beziehungen vor allem durch die periphere Lage Livlands zum Reich verursacht. Für den Orden in Livland war die Anlehnung an den deutschen Zweig eine gute Möglichkeit, dieses geographische und politische Defizit zu vermindern. Ein sehr gutes Beispiel dafür ist die entscheidende Rolle der Deutschherren bei der Erlangung der Reichsregalien für den Meister Plettenberg. Später aber konnte der livländische Meister mit Hilfe des deutschen Zweiges seine Interessen besser auf den Reichstagen vertreten als der Erzbischof Wilhelm von Riga, obwohl dieser mächtige Verwandte im Reich wie der Kurfürst von Brandenburg hatte. Allerdings konnte auch der deutsche Zweig von der Kooperation mit den Livländern profitieren. Bei einer möglichen Rückeroberung Preußens hätte Livland eine entscheidende Rolle gespielt. Die Ar-

${ }^{121}$ Herrmann, Der Deutsche Orden, 217. 
gumente des Administrators waren sicherlich gewichtiger, wenn er behauptete, dass auch der livländische Meister, der eigentliche Fürstenmacht innehatte, ihn unterstützte. Die konkrete Zusammenarbeit erwies sich aber als problematisch, da die Livländer sich nicht an der Vertretung bei Kaiser und Papst beteiligen wollten - wahrscheinlich wegen der Kosten, aber vielleicht auch deshalb, weil sie sich nicht formell und direkt mit dem deutschen Zweig verbinden wollten.

Somit muss man bei einer Betrachtung der Beziehungen auf und neben den Reichstagen Axel Herrmann zustimmen, dass die Verbindungen zwischen den livländischen und deutschen Ordenszweigen eher kühl und unregelmäßig blieben, weil die wichtigsten Interessen und Problemfelder für beide Zweige nur teilweise zusammenfielen. Der deutsche Zweig war fest mit den Strukturen des Reichs verbunden, während der livländische Zweig vor allem mit den innen- und außenpolitischen Realitäten Livlands zu tun hatte. Andererseits hatten die Ordenszweige keine ernsteren Konkurrenzfelder und ihre Zusammenarbeit scheint besonders während der Krisezeiten wie Koadjutorfehde recht bedeutsam gewesen zu sein. Die Integration Livlands ins Reich nahm während des I6. Jahrhunderts zu (wie auch die nach I 544 zur Regel gewordene Reichstagsteilnahme der livländischen Ordensgesandten zeigt), und es ist möglich, dass im Laufe der Zeit die beiden Zweige mehr gemeinsame Interessen wegen dieser Tendenz hätten entwikkeln können. ${ }^{122}$ Allerdings endete Livlands Zusammenwachsen mit dem Reich bei Beginn des Livländischen Kriegs abrupt.

122 Beispielsweise wurden mehrere norddeutsche Gebiete erst bis zum Anfang des 17. Jahrhunderts in die Reichsstrukturen integriert, vgl. Die Integration des südlichen Ostseeraumes in das alte Reich, hrsg. v. Nils Jörn und Michael North, Quellen und Forschungen zur höchsten Gerichtsbarkeit im alten Reich 35 (Köln: Böhlau, 2000). 


\section{ANHANG}

Tabelle: Ordensgesandte auf den Reichstagen I 52 I- I $559^{*}$

\begin{tabular}{|c|c|c|c|c|c|}
\hline Reichstag & $\begin{array}{c}\text { HOCHMEI- } \\
\text { STER }\end{array}$ & \begin{tabular}{|c|} 
DEUTSCHMEI- \\
STER (SEIT I 527 \\
ADMINISTRA- \\
TOR) \\
\end{tabular} & $\begin{array}{c}\text { Meister Von } \\
\text { LIVland }\end{array}$ & $\begin{array}{l}\text { LANDKOM- } \\
\text { TUR VON } \\
\text { KOBLENZ }\end{array}$ & $\begin{array}{c}\text { LANDKOMTUR } \\
\text { VON ELSASS- } \\
\text { BURGUND }\end{array}$ \\
\hline I52I Worms & & $\begin{array}{l}\text { persönlich an- } \\
\text { wesend }\end{array}$ & & $\begin{array}{l}\text { persönlich } \\
\text { anwesend }^{\mathrm{i}}\end{array}$ & $\begin{array}{l}\text { Dr. Heinrich } \\
\text { Winkelhofer }\end{array}$ \\
\hline I 522 Nürnberg & & $\begin{array}{l}\text { Komture von } \\
\text { Virnsberg und } \\
\text { Frankfurt }^{2}\end{array}$ & & & $\begin{array}{l}\text { Abt von Kais- } \\
\text { heim; Dr. } \\
\text { Marsilius Bon- } \\
\text { ningen }^{3} \\
\end{array}$ \\
\hline I $522 / 23$ Nürnberg & $\begin{array}{l}\text { persönlich } \\
\text { anwesend }^{4}\end{array}$ & "der von Bibra"s & & $\begin{array}{l}\text { persönlich } \\
\text { anwesend }^{6}\end{array}$ & $\begin{array}{l}\text { Abt von Wein- } \\
\text { garten; Marsilius } \\
\text { Breninger }^{7}\end{array}$ \\
\hline I 524 Nürnberg & $\begin{array}{l}\text { persönlich } \\
\text { anwesend }^{8}\end{array}$ & $\begin{array}{l}\text { persönlich } \\
\text { anwesend }\end{array}$ & & & $\begin{array}{l}\text { Äbte von Wein- } \\
\text { garten und } \\
\text { Marchtal }\end{array}$ \\
\hline 1525/26 Augsburg & & $\begin{array}{l}\text { Komtur von Blu- } \\
\text { menthal }^{\text {1॰ }}\end{array}$ & & & \\
\hline I526 Speyer & & \begin{tabular}{|l|} 
Komtur von \\
Frankfurt; Ober- \\
marschall $^{11}$ \\
\end{tabular} & & & $\begin{array}{l}\text { Abt von Wein- } \\
\text { garten }\end{array}$ \\
\hline 1527 Regensburg & & $\begin{array}{l}\text { Komtur von Blu- } \\
\text { menthal }\end{array}$ & $\begin{array}{l}\text { [Erzbischof von } \\
\text { Riga, Bischof von } \\
\text { Kurland }]^{12} \\
\end{array}$ & $\begin{array}{l}\text { Abt von } \\
\text { Weingarten }^{13}\end{array}$ & $\begin{array}{l}\text { Abt von Wein- } \\
\text { garten }\end{array}$ \\
\hline I 529 Speyer & \multicolumn{2}{|c|}{ persönlich anwesend ${ }^{14}$} & $\begin{array}{l}\text { [entschuldigt } \\
\text { durch Admini- } \\
\text { strator] }\end{array}$ & & Johann König \\
\hline I530 Augsburg & \multicolumn{2}{|c|}{ persönlich anwesend } & $\begin{array}{l}\text { Hauskomtur von } \\
\text { Riga; Kanzler }{ }^{15} \\
\end{array}$ & & Administrator \\
\hline I532 Regensburg & \multicolumn{2}{|c|}{ persönlich anwesend } & $\begin{array}{l}\text { [entschuldigt } \\
\text { durch Admini- } \\
\text { strator] }\end{array}$ & & Administrator \\
\hline
\end{tabular}

* Die Angaben stammen größtenteils aus folgenden Veröffentlichungen: Demel, “Die Reichstagsgesandten des Deutschen Ordens"; ders., "Zur Reichspolitik"; Aulinger und Schweinzer-Burian, Habsburgische und reichsständische Präsenz. Bei Abweichungen wird auf die benutzte Quelle verwiesen. 
Tabelle: Ordensgesandte auf den Reichstagen I 52 I - I 559

\begin{tabular}{|c|c|c|c|c|c|}
\hline Reichstag & $\begin{array}{l}\text { HOCHMEI- } \\
\text { STER }\end{array}$ & \begin{tabular}{|} 
DEUTSCHMEI- \\
STER (SEIT I 527 \\
ADMINISTRA- \\
TOR)
\end{tabular} & $\begin{array}{l}\text { MEISTER VON } \\
\text { LIVLAND }\end{array}$ & $\begin{array}{l}\text { LANDKOM- } \\
\text { TUR VON } \\
\text { KOBLENZ }\end{array}$ & $\begin{array}{c}\text { LANDKOMTUR } \\
\text { VON ELSASS- } \\
\text { BURGUND }\end{array}$ \\
\hline I54I Regensburg & \multicolumn{2}{|c|}{ persönlich anwesend } & $\begin{array}{l}\text { [entschuldigt } \\
\text { durch Admini- } \\
\text { strator] }\end{array}$ & $\begin{array}{l}\text { Komtur von } \\
\text { Köln }^{16}\end{array}$ & Administrator \\
\hline I 542 Speyer & \multicolumn{2}{|c|}{ persönlich anwesend } & $\begin{array}{l}\text { [Sekretär beim } \\
\text { König }]^{17}\end{array}$ & & Administrator \\
\hline I 542 Nürnberg & \multicolumn{2}{|c|}{ persönlich anwesend } & & $\begin{array}{l}\text { Administra- } \\
\text { tor }\end{array}$ & Administrator \\
\hline I 543 Nürnberg & \multicolumn{2}{|c|}{$\begin{array}{l}\text { LK Hessen } ;{ }^{18} \text { Kanzler; }{ }^{19} \text { Jurist } \\
\text { Reinhard von Haussen }\end{array}$} & & $\begin{array}{l}\text { Reinhard von } \\
\text { Haussen }\end{array}$ & $\begin{array}{l}\text { Reinhard von } \\
\text { Haussen }\end{array}$ \\
\hline I 544 Speyer & \multicolumn{2}{|c|}{ persönlich anwesend } & $\begin{array}{l}\text { Komtur von Ma- } \\
\text { rienburg und } \\
\text { Kanzler }^{20} \\
\end{array}$ & $\begin{array}{l}\text { persönlich } \\
\text { anwesend }^{21}\end{array}$ & \\
\hline I 545 Worms & \multicolumn{2}{|c|}{ persönlich anwesend } & Sekretär ${ }^{22}$ & $\begin{array}{l}\text { persönlich } \\
\text { anwesend }^{23}\end{array}$ & \\
\hline I546 Regensburg & \multicolumn{2}{|c|}{ persönlich anwesend } & $\begin{array}{l}\text { Administrator als } \\
\text { Vertreter }\end{array}$ & & \\
\hline I 547/48 Augsburg & \multicolumn{2}{|c|}{ persönlich anwesend } & $\begin{array}{l}\text { Philipp von der } \\
\text { Brüggen; Se- } \\
\text { kretär }\end{array}$ & & \\
\hline I550/5 I Augsburg & \multicolumn{2}{|c|}{ persönlich anwesend } & $\begin{array}{l}\text { Philipp von der } \\
\text { Brüggen; Se- } \\
\text { kretär }\end{array}$ & DM-Kanzler & $\begin{array}{l}\text { persönlich an- } \\
\text { wesend }^{24}\end{array}$ \\
\hline 1555 Augsburg & \multicolumn{2}{|c|}{$\begin{array}{l}\text { LK Elsass; }{ }^{25} \text { Komtur Blu- } \\
\text { menthal;:;6 Jurist Thomas } \\
\text { Maierhofer }\end{array}$} & $\begin{array}{l}\text { Hauskomtur von } \\
\text { Riga }^{27}\end{array}$ & & $\begin{array}{l}\text { persönlich an- } \\
\text { wesend }\end{array}$ \\
\hline $\begin{array}{l}\text { 1556/57 Regens- } \\
\text { burg }\end{array}$ & \multicolumn{2}{|c|}{ persönlich anwesend } & $\begin{array}{l}\text { Hauskomtur von } \\
\text { Riga; Sekretär }{ }^{28}\end{array}$ & & $\begin{array}{l}\text { persönlich an- } \\
\text { wesend }\end{array}$ \\
\hline I558/59 Augsburg & \multicolumn{2}{|c|}{ persönlich anwesend ${ }^{29}$} & $\begin{array}{l}\text { Komtur von } \\
\text { Dünaburg }\end{array}$ & $\begin{array}{l}\text { persönlich } \\
\text { anwesend }^{3 \circ}\end{array}$ & $\begin{array}{l}\text { persönlich an- } \\
\text { wesend }\end{array}$ \\
\hline
\end{tabular}

1 Landkomtur Ludwig von Seinsheim als Vertreter des Erzbischofs von Köln. I $522 /$ I 523 war er auch anwesend.

2 Wolfgang von Bibra und Walter von Cronberg.

3 Deutsche Reichstagsakten unter Kaiser Karl V., 3 , hrsg. v. Wrede, I 83.

4 Mit ihm war auch Erich von Braunschweig anwesend.

5 Wahrscheinlich Wolfgang von Bibra. 
6 Wie I 52 I, vgl. Deutsche Reichstagsakten unter Kaiser Karl V., 3, hrsg. v. Wrede, 283, 756.

7 Wahrscheinlich Bonningen.

8 Mit den Gesandten Georg von Klingenbeck und Johann Fischer.

9 Deutsche Reichstagsakten unter Kaiser Karl V., 4, hrsg. v. Wrede, 6 $12,623$.

10 Friedrich Sturmfeder. I $525 /$ i 526 war er auch als Vertreter anwesend.

1 Walter von Cronberg und Georg von Eltz.

12 Johannes von Blankenfeld (Erzbischof von Riga und Bischof von Dorpat); Hermann Ronneberg.

13 Auch der Statthalter zu Koblenz, Wilhelm Graf von Isenburg, war anwesend.

${ }_{14}$ Mit anderen Ordensleuten (darunter Obermarschall Georg von Eltz und weitere Komture).

is Dietrich von Balen gen. Fleck und Friedrich Schneeberg.

16 Werner Forstmeister von Gelnhausen.

17 Georg von dem Walde ersuchte erfolgreich um eine Konfirmation für Johann von der Recke, den Koadjutor des Landmeisters.

18 Wolfgang von Schutzbar gen. Milchling.

19 Gregor Spiess, I 550/ 155 I Vertreter des Landkomturs von Koblenz.

20 Jasper von Munster und Dr. Hermann Falck. In Reichstagsverhandlungen kommen sie nicht hervor, aber sie wurden in einem Brief des Stadtsekretärs von Riga an Erzbischof Wilhelm von Riga erwähnt (Herzog Albrecht von Preußen und Livland (I540-I55I). Regesten aus dem Herzoglichen Briefarchiv und den Ostpreußischen Folianten, hrsg. v. Stefan Hartmann, Veröffentlichungen aus den Archiven Preußischer Kulturbesitz 54 (Köln-Weimar-Wien: Böhlau, 2002), 24I Nr. I 259/I).

${ }_{21}$ Landkomtur Walter von Heusenstamm.

22 Matthias Heuroder, auch I 547/ I 548 und I $550 /$ i 55 I.

23 Landkomtur Wilhelm Halber von Hergern und Dr. Matthias Rasch.

24 Sigmund von Hornstein (auch I555 bis I 559); I 550/I55 I auch Johann Jakob Freiherr zu Königseck und Aulendorf.

25 Siegmund von Hornstein.

26 Johann von Ehingen.

${ }_{27}$ Georg Syburg zu Wischlingen, auch I 556/ 557 und I 559 (damals als Komtur von Dünaburg).

28 Michael Brückner.

29 Auch Kanzler Thomas Maierhofer.

30 Landkomtur Anton von Wyer zu Nickendeich.

\section{PRIMARY SOURCES:}

Berlin. Geheimes Staatsarchiv Preußischer Kulturbesitz. XX. Hauptabteilung, Ordensbriefarchiv, Nrn. 19457, 19727, 24971, 24985, 25056, 25072, 25095, 25122, 25292, 25456, 255 I 5a, 25904, 26002, 26572, 26705, 26706, 27226, 27349, 275 I 4.

Akten und Rezesse der livländischen Ständetage. Bd. I, 5. Lief. (I450-1454). Herausgegeben von Leonid Arbusow, jun. Riga: Jonck \& Poliewsky, 1929.

Akten und Rezesse der livländischen Ständetage. Bd. 3. (1494-1535). Herausgegeben von Leonid Arbusow, sen. Riga: Deubner, 1910. 
Die Apologien Herzog Albrechts. Herausgegeben von Almut Bues. Quellen und Studien. Deutsches Historisches Institut Warschau 20. Wiesbaden: Harrassowitz, 2009.

"Auctarium II. Indicis Corporis Historico-Diplomatici et Epistolaris Livoniae, Esthoniae,

Curoniae." Herausgegeben von Karl Eduard Napiersky. Mittheilungen aus dem Gebiete der Geschichte Liv-, Ehst- Und Kurland's 2 ( I 842): 485-544.

Die Beschwerden der deutschen Nation auf den Reichstagen der Reformationszeiten (I52I-1530). Herausgegeben von Annelies Grundmann und Rosemarie Aulinger. Deutsche Reichstagsakten. Jüngere Reihe: Deutsche Reichstagsakten unter Kaiser Karl V. 2 I.

München: De Gruyter, 20 I 5.

Deutsche Reichstagsakten unter Kaiser Karl V. Bd. 2. Herausgegeben von Adolf Wrede.

Deutsche Reichstagsakten. Jüngere Reihe: Deutsche Reichstagsakten unter Kaiser Karl V. 2. Gotha: Perthes, I 896.

Deutsche Reichstagsakten unter Kaiser Karl $V$. Bd. 3. Herausgegeben von Adolf Wrede.

Deutsche Reichstagsakten. Jüngere Reihe: Deutsche Reichstagsakten unter Kaiser Karl V. 3. Gotha: Perthes, I 901.

Deutsche Reichstagsakten unter Kaiser Karl V. Bd. 4. Herausgegeben von Adolf Wrede.

Deutsche Reichstagsakten. Jüngere Reihe: Deutsche Reichstagsakten unter Kaiser Karl V. 4. Gotha: Perthes, 1905.

Deutsche Reichstagsakten unter Kaiser Karl V. Bd. 7. Herausgegeben von Johannes Kühn.

Deutsche Reichstagsakten. Jüngere Reihe: Deutsche Reichstagsakten unter Kaiser Karl V. 7. Göttingen: Vandenhoeck und Ruprecht, I 935.

Deutsche Reichstagsakten unter Kaiser Karl V. Bd. 8. Herausgegeben von Wolfgang Steglich. Deutsche Reichstagsakten. Jüngere Reihe: Deutsche Reichstagsakten unter Kaiser Karl V. 8. Göttingen: Vandenhoeck und Ruprecht, I 970/1 97 I.

Handlingar till Nordens historia ISIS-I523. Bd. II. Juli ISI8-december I5I9. Tl. I. Julidecember ISI8. Herausgegeben von Lars Sjödin. Historiska handlingar 2. Stockholm: Norstedt, I 977.

Handlingar till Nordens historia ISIS-I523. Bd. II. Juli ISI8-december ISI9. Tl. 2. ISI9. Herausgegeben von Lars Sjödin. Historiska handlingar 2. Stockholm: Norstedt, I 979. Herzog Albrecht von Preußen und Livland (I540-I55I): Regesten aus dem Herzoglichen Briefarchiv und den ostpreussischen Folianten. Herausgegeben von Stefan Hartmann. Veröffentlichungen aus den Archiven Preußischer Kulturbesitz 54. Köln-Weimar-Wien: Böhlau, 2002.

Liv-, Est-und Kurländisches Urkundenbuch. Abt. 2. Bd. I. I494 Ende Mai-I5oo. Herausgegeben von Leonid Arbusow, sen. Riga-Moskau: Deubner, I 900.

Liv-, Est-und Kurländisches Urkundenbuch. Abt. 2, Bd. II. I 50I-I 505. Herausgegeben von Leonid Arbusow, sen. Riga-Leipzig: Deubner, I 905.

Neue und vollständigere Sammlung der Reichs-Abschiede, Welche von den Zeiten Kayser Conrads II. bis jetzo, auf den Teutschen Reichs-Tägen abgefasset worden, sammt den wichtigsten Reichs-Schlüssen, so auf dem noch fürwährenden Reichs-Tage zur Richtigkeit gekommen sind. Bd. 2. Reichs-Abschiede von dem Jahr I495. bis auf das Jahr ISSI. 
inclusive. Herausgegeben von Heinrich Christian von Senckenberg und Johann Jacob Schmauss. Frankfurt/Main: Koch, 1747.

Nordosteuropa und der Deutsche Orden: Kurzregesten. Bd. I. bis I56I. Herausgegeben von Klemens Wieser. Quellen und Studien zur Geschichte des Deutschen Ordens I 7. Bad Godesberg-Bonn: Wissenschaftliches Archiv, 1969.

Regesta historico-diplomatica Ordinis S. Mariae Theutonicorum, IIg8-I525. Pars I. Index Tabularii Ordinis S. Mariae Theutonicorum. Regesten zum Ordensbriefarchiv. Vol. 3. I5II-I525. Herausgegeben von Erich Joachim und Walter Hubatsch. Göttingen: Vandenhoeck und Ruprecht, 1973.

Der Reichstag in Regensburg und die Verhandlungen über einen Friedstand mit den Protestanten in Schweinfurt und Nürnberg I532. Tl. I-3. Herausgegeben von Rosemarie Aulinger. Deutsche Reichstagsakten. Jüngere Reihe: Deutsche Reichstagsakten unter Kaiser Karl V. ı o. Göttingen: Vandenhoeck \& Ruprecht, 1992.

Reichstag von Worms 1495. Tl. I-3. Herausgegeben von Heinz Angermeier. Deutsche Reichstagsakten. Mittlere Reihe 5. Göttingen: Vandenhoeck \& Ruprecht, I 98 I.

Der Reichstag zu Augsburg I525, der Reichstag zu Speyer I526, der Fürstentag zu Esslingen I526. Herausgegeben von Rosemarie Aulinger. Deutsche Reichstagsakten. Jüngere Reihe: Deutsche Reichstagsakten unter Kaiser Karl V. 5/6. München: Oldenbourg, $20 \mathrm{I}$.

Der Reichstag zu Augsburg I547/48. Tl. I-3. Herausgegeben von Ursula Machoczek. Deutsche Reichstagsakten. Jüngere Reihe: Deutsche Reichstagsakten unter Kaiser Karl V. i 8. München: Oldenbourg, 2005.

Der Reichstag zu Augsburg I5so/sI. Herausgegeben von Erwein Eltz. Deutsche Reichstagsakten. Jüngere Reihe: Deutsche Reichstagsakten unter Kaiser Karl V. i 9. München: Oldenbourg, 2005.

Der Reichstag zu Augsburg I555. Tl. I -4. Herausgegeben von Rosemarie Aulinger, Erwein Eltz, und Ursula Machoczek. Deutsche Reichstagsakten. Jüngere Reihe: Deutsche Reichstagsakten unter Kaiser Karl V. 20. München: Oldenbourg, 2009.

Der Reichstag zu Köln Isos. Tl. I-2. Herausgegeben von Dietmar Heil. Deutsche Reichstagsakten. Mittlere Reihe 8. München: Oldenbourg, 2008.

Der Reichstag zu Nürnberg I 542. Herausgegeben von Silvia Schweinzer-Burian. Deutsche Reichstagsakten. Jüngere Reihe: Deutsche Reichstagsakten unter Kaiser Karl V. I 3. München: Oldenbourg, 20 I 0.

Der Reichstag zu Regensburg I 54I. Herausgegeben von Albrecht P. Lutterberger und Christiane Neerfeld. Deutsche Reichstagsakten. Jüngere Reihe: Deutsche Reichstagsakten unter Kaiser Karl V. I I. Berlin-Boston: De Gruyter Oldenbourg, 20 I 8.

Der Reichstag zu Regensburg 1546. Herausgegeben von Rosemarie Aulinger. Deutsche Reichstagsakten. Jüngere Reihe: Deutsche Reichstagsakten unter Kaiser Karl V. I 7. München: Oldenbourg, 2005.

Der Reichstag zu Regensburg I556/57. Herausgegeben von Josef Leeb. Deutsche Reichstagsakten. Reichsversammlungen I 556-I 662. München: Oldenbourg, 20 I 3. 
Der Reichstag zu Speyer 1542. Tl. I-2. Herausgegeben von Silvia Schweinzer-Burian. Deutsche Reichstagsakten. Jüngere Reihe: Deutsche Reichstagsakten unter Kaiser Karl V. I 2. München: Oldenbourg, 2003.

Der Reichstag zu Worms I509. Herausgegeben von Dietmar Heil. Deutsche Reichstagsakten. Mittlere Reihe I o. Berlin; Boston: De Gruyter Oldenbourg, 2017.

Der Reichstag zu Worms I545. Herausgegeben von Rosemarie Aulinger. Deutsche Reichstagsakten. Jüngere Reihe: Deutsche Reichstagsakten unter Kaiser Karl V. I6. München: Oldenbourg, 2003.

Der Speyrer Reichstag von I544. Tl. I-4. Herausgegeben von Erwein Eltz. Deutsche Reichstagsakten. Jüngere Reihe: Deutsche Reichstagsakten unter Kaiser Karl V. I 5. Göttingen: Vandenhoeck \& Ruprecht, 200 I.

Die Türkensteuer im Herzogthum Preußen I540. Bd. I. Fischhausen - Schaaken - Neuhausen - Labiau. Herausgegeben von Hans Heinz Diehlmann. Hamburg: Verein für Familienforschung in Ost- und Westpreußen, 1998.

Die Türkensteuer im Herzogthum Preußen I 540. Bd. 2. Memel - Tilsit. Herausgegeben von Hans Heinz Diehlmann. Hamburg: Verein für Familienforschung in Ost- und Westpreußen, 2006.

Die Türkensteuer in Herzogtum Preußen I540, Bd. 3. Ragnit, Insterburg, Georgenburg und Saalau. Herausgegeben von Hans Heinz Diehlmann. Hamburg: Verein für Familienforschung in Ost- u. Westpreußen, 2008.

Die Urkunden des Deutschordenszentralarchivs in Wien: Regesten. Tlbd. III. Dezember I4I 8 - Dezember I526. Herausgegeben von Marian Tumler und Udo Arnold. Quellen und Studien zur Geschichte des Deutschen Ordens 60, III. Marburg: Elwert, 2007.

Die Urkunden des Deutschordenszentralarchivs in Wien: Regesten. Tlbd. IV. Januar I527-April I597. Herausgegeben von Marian Tumler und Udo Arnold. Quellen und Studien zur Geschichte des Deutschen Ordens 60, IV. Weimar: VDG, 20 I 9.

Das virtuelle Preußische Urkundenbuch: Regesten und Texte zur Geschichte Preußens und des Deutschen Ordens. Herausgegeben von Jürgen Sarnowsky, I 999-202 I. Zugegriffen am 9. März 202 I. https://www.spaetmittelalter.uni-hamburg.de/Urkundenbuch/

\section{SECONDARY SOURCES:}

Arbusow, jun., Leonid. Wolter von Plettenberg und der Untergang des Deutschen Ordens in Preussen. Eine Studie aus der Reformationszeit Livlands. Schriften des Vereins für Reformationgeschichte 36/2. Leipzig-Halle: Karras, I 9 I 9.

Arnold, Udo. "Hochmeisterverlust, Bauernunruhen und Reformation - Krisenbewältigung unter den Deutschmeistern Dietrich von Cleen und Walter von Cronberg." In Die Ritterorden in Umbruchs-und Krisenzeiten, herausgegeben von Roman Czaja und Jürgen Sarnowsky, 24 I-257. Ordines Militares. Colloquia Torunensia Historica XVI. Toruń: Wydawnictwo Naukowe Uniwersytetu Mikołaja Kopernika, 20 I I. 
Arnold, Udo. "Livland als Glied des Deutschen Ordens in der Epoche Wolters von Plettenberg." In Wolter von Plettenberg: Der Grösste Ordensmeister Livlands, herausgegeben von Norbert Angermann, 23-46. Lüneburg: Verlag Nordostdeutsches Kulturwerk, I 985 .

Arnold, Udo. "Mergentheim und Königsberg/Berlin - die Rekuperationsbemühungen des Deutschen Ordens auf Preußen." Württembergisch Franken 60 (1976): 1 4-54.

Aulinger, Rosemarie und Silvia Schweinzer-Burian. Habsburgische und reichsständische Präsenz auf den Reichstagen I52I-I555, 201 I. Zugegriffen am 8. März 202 I. https:// www.historischekommission-muenchen.de/fileadmin/user_uON_BACKUP/pdf/ abteilungen/staendetabelle_I 52 I_I 555 .pdf.

Baranov, Alexander. "Zwischen Bündnis und Konfrontation. Der livländische Ordensmeister Bernd von der Borch und Großfürst Ivan III. von Moskau (I 47 I - I 483).” In Akteure mittelalterlicher Außenpolitik. Das Beispiel Ostmitteleuropas, herausgegeben von Stephan Flemming und Norbert Kersken, I27-I44. Tagungen zur Ostmitteleuropaforschung 35. Marburg: Herder, 2017.

Bergengrün, Alexander. Herzog Christoph von Mecklenburg, letzter Koadjutor des Erzbistums Riga: ein Beitrag zur livländischen und mecklenburgischen Geschichte. Reval: Kluge, I 898 .

Biskup, Marian. "Der Deutsche Orden im Reich, in Preussen und Livland im Banne habsburgischer Politik in der zweiten Hälfte des I 5 . und zu Beginn des I 6. Jahrhunderts." In Die Ritterorden zwischen geistlicher und weltlicher Macht im Mittelalter, herausgegeben von Zenon H. Nowak, I I I - 25 . Ordines Militares. Colloquia Torunensia Historica V. Toruń: Wydawnictwo Uniwersytetu Mikołaja Kopernika, I 990.

Bonnel, Ernst. "Das freundschaftliche Verhältniss zwischen dem Deutschmeister zu Mergentheim und den livländischen Ordensobern zur Zeit der Reformation.” Mittheilungen aus dem Gebiete der Geschichte Liv-, Ehst-und Kurland's 9 ( I 860): 7 I -8 I.

Boockmann, Hartmut. "Die Briefe des Deutschordenshochmeisters." In Kommunikationspraxis und Korrespondenzwesen im Mittelalter und in der Renaissance, herausgegeben von Hans-Dieter Heimann und Ivan Hlaváček, I03-I I 2. Paderborn: Schöningh, I 998.

Boockmann, Hartmut. "Die Vertretung des Deutschen Ordens auf den spätmittelalterlichen Reichstagen." In Nord und Süd in der deutschen Geschichte des Mittelalters, herausgegeben von Werner Paravicini, 97-108. Kieler Historische Studien 34. Sigmaringen: Thorbecke, I 990.

Borchardt, Karl. "Die Erhebungen zum Reichsfürsten für den Deutschmeister I 494 und für den Johannitermeister i 548." In Von Hamburg nach Java, herausgegeben von Jochen Burgtorf, Christian Hoffarth, und Sebastian Kubon, 427-442. Nova Mediaevalia I 8. Göttingen: Vandenhoeck und Ruprecht, 2020.

Brünjes, Holger S. Die Deutschordenskomturei in Bremen. Ein Beitrag zur Geschichte des Ordens in Livland. Quellen und Studien zur Geschichte des Deutschen Ordens 53. Marburg: Elwert, I 997. 
Demel, Bernhard. "Die Reichstagsgesandten des Deutschen Ordens von I 495 bis Ende I 805." In Ders., Der Deutsche Orden im Spiegel seiner Besitzungen und Beziehungen in Europa, 604-656. Europäische Hochschulschriften. Reihe 3, Geschichte und ihre Hilfswissenschaften 96r. Frankfurt/Main: Lang, 2004.

Demel, Bernhard. "Die Rekuperationsbemühungen des Deutschen Ordens um Livland von I 558/62 bis zum Ende des I 8. Jahrhunderts." In Ders., Der Deutsche Orden im Spiegel seiner Besitzungen und Beziehungen in Europa, 190-258. Europäische Hochschulschriften. Reihe 3, Geschichte und ihre Hilfswissenschaften 961. Frankfurt/ Main: Lang, 2004.

Demel, Bernhard. "Zur Reichspolitik des livländischen Ordenszweiges in den Jahren I 52 I bis 1561/1 562." Ordines Militares Colloquia Torunensia Historica. Yearbook for the Study of the Military Orders 20 (2016): 1 45-172.

Diestelkamp, Bernhard. "Eine versuchte Annäherung Zar Iwans IV., des Schrecklichen, an den Westen? Ein Reichskammergerichtsprozeß, der dies nahelegt”. In Reich, Regionen und Europa in Mittelalter und Neuzeit. Festschrift für Peter Moraw, herausgegeben von Paul-Joachim Heinig, Sigrid Jahns, Hans-Joachim Schmidt, Rainer Christoph Schwinges, und Sabine Wefers, 305-322. Historische Forschungen 67. Berlin: Duncker \& Humblot, 2000.

Dopkewitsch, Helene. "Die Hochmeisterfrage und das Livlandproblem nach der Umwandlung des Ordenslandes Preußen in ein weltliches Herzogtum durch den Krakauer Vertrag von April I 525." Zeitschrift für Ostforschung I 6, H. 2 (1 967): 20 I -255.

Dorn, Hans J. Die Deutschordensballei Westfalen von der Reformation bis zu ibrer Auflösung im Jahre 1809. Quellen und Studien zur Geschichte des Deutschen Ordens 26. Marburg: Elwert, I 978.

Forstreuter, Kurt. Vom Ordensstaat zum Fürstentum. Geistige und politische Wandlungen im Deutschordensstaate Preußen unter den Hochmeistern Friedrich und Albrecht (1498-1525). Kitzingen: Holzner, I 95 I.

Genealogisches Handbuch der baltischen Ritterschaften. Tl. 3. Kurland, Bd. I. Herausgegeben von Verband des kurländischen Stammadels, bearbeitet von Oskar Stavenhagen. Görlitz: Verlag für Sippenforschung und Wappenkunde C. A. Starke, I 937-1 939.

Götz, Johannes. "Das Archiv des livländischen Deutschordenszweiges. Eine archivgeschichtliche Untersuchung." In Die Kirche im mittelalterlichen Livland, herausgegeben von Radosław Biskup, Johannes Götz, und Andrzej Radzimiński, 9-77. Ecclesia Clerusque Temporibus Medii Aevii 5. Toruń: Wydawnictwo Naukowe Uniwersytetu Mikołaja Kopernika, 20 I 9.

Götz, Johannes. "Die Wahl des livländischen Meisters: Ein Indikator für das Verhältnis zwischen Zentrum und Provinz im Deutschen Orden.” Forschungen zur baltischen Geschichte I 4 (2019): I I 70.

Götz, Johannes. "Verbunden mit der Marienburg. Livländischer und preußischer Deutschordenszweig bis zum Ausbruch des Zungenstreits i 438." In Livland - eine Region am Ende der Welt? Forschungen zum Verhältnis zwischen Zentrum und Peripherie im späten Mittelalter / Livonia - a Region at the End of the World? Studies on the Relations 
between Centre and Periphery in the Later Middle Ages, herausgegeben von Anti Selart und Matthias Thumser, 37 I-4I 4. Quellen und Studien zur baltischen Geschichte 27. Köln-Weimar-Wien: Böhlau, 2017.

Graßmann, Antjekathrin. Preußen und Habsburg im 16. Jabrhundert. Studien zur Geschichte Preußens I 5. Köln-Berlin: Grote’sche Verlagsbuchhandlung, 1968.

Hartmann, Stefan. "Neue Quellen zur livländischen Koadjutorfehde i 555/6." In Aus der Geschichte Alt-Livlands: Festschrift für Heinz von zur Müblen zum go. Geburtstag, herausgegeben von Bernhart Jähnig und Klaus Militzer, 275-306. Schriften der Baltischen Historischen Kommission. Münster: Lit, 2004.

Heckmann, Marie-Luise. "Herzog Albrecht und die Reformation in Preußen - im Spiegel von Selbstzeugnissen." Preußenland N.F. 9 (20 1 8): 59-88.

Hellmann, Manfred. "Gesandte des Deutschen Ordens am Hofe Ivans IV. (I 564)." In Russland und Deutschland: Aufsätze, herausgegeben von Uwe Liszkowski, 38-50. Kieler Historische Studien 22. Stuttgart: Klett, 1974.

Herrmann, Axel. Der Deutsche Orden unter Walter von Cronberg (I525-I543). Zur Politik und Struktur der "teutschen Adels Spitale" im Reformationszeitalter. Quellen und Studien zur Geschichte des Deutschen Ordens 35. Bonn-Bad Godesberg: Verlag Wissenschaftliches Archiv, 1974.

Hildebrand, Hermann. Die Arbeiten für das Liv-, Est-und Kurländische Urkundenbuch im Jahre I 875/76. Riga: Müller, I 877.

Hofmann, Hanns H. Der Staat des Deutschmeisters. Studien zu einer Geschichte des Deutschen Ordens im Heiligen Römischen Reich Deutscher Nation. München: Kommission für Bayerischen Landesgeschichte, 1964.

Hubatsch, Walter. Albrecht von Brandenburg-Ansbach, Deutschordens-Hochmeister und Herzog in Preußen 1490-I568. Studien zur Geschichte Preußens 8. Heidelberg: Quelle \& Meyer, 1960.

Die Integration des südlichen Ostseeraumes in das alte Reich. Herausgegeben von Nils Jörn und Michael North. Quellen und Forschungen zur höchsten Gerichtsbarkeit im alten Reich 35. Köln: Böhlau, 2000.

Israel, Ottokar. Das Verbältnis des Hochmeisters des Deutschen Ordens zum Reich im IS. Jahrhundert. Wissenschaftliche Beiträge zur Geschichte und Landeskunde Ost-Mitteleuropas 4. Marburg/Lahn: Herder-Institut, 1952.

Jähnig, Bernhart. Verfassung und Verwaltung des Deutschen Ordens und seiner Herrschaft in Livland. Schriften der Baltischen Historischen Kommission I 6. Berlin: Lit, 20 I I. Joachim, Erich. Die Politik des letzten Hochmeisters in Preussen Albrecht von Brandenburg. Tl. I. I5I0-I5I7. Publikationen aus den königlich-preußischen Staatsarchiven 50. Leipzig: Hirzel, I 892.

Joachim, Erich. Die Politik des letzten Hochmeisters in Preussen Albrecht von Brandenburg. Tl. 2. ISI8-IS2I. Publikationen aus den königlich-preußischen Staatsarchiven 58. Leipzig: Hirzel, I 894. 
Joachim, Erich. Die Politik des letzten Hochmeisters in Preussen Albrecht von Brandenburg. Tl. 3. I52I-I525. Publikationen aus den königlich-preußischen Staatsarchiven 6I. Leipzig: Hirzel, I 895.

Karge, Paul. "Die Berufung des Markgrafen Wilhelm zum Koadjutor des Rigaschen Erzbichofs: ein Beitrag zur Reformationsgeschichte." Baltische Monatsschrift 6 I (1906): I $17-156$.

Kḷava, Valda. "Livonija Svētajā Romas impērijā: problēmas izpēte un attiecību piemērs no I 6. gadsimta vidus." Latvijas Vēstures Institūta Žurnāls I (2014): I 26 - I 55.

Kreem, Juhan. "Das Augsburger Interim in Livland. Evangelische und Altgläubige in den baltischen Landen in der Mitte des 16. Jahrhunderts." Historisches Jahrbuch 134 (20I4): I I I-I I I.

Kreem, Juhan. "Der Deutsche Orden in Livland im I 6. Jahrhundert: Einige Betrachtungen zur Entwicklung seines Personalbestandes." Jahrbuch für die Geschichte Mittel- und Ostdeutschlands 5 I (2009): 77-89.

Kreem, Juhan. "Der Gehorsam der Gebietiger gegenüber dem livländischen Meister im I6. Jahrhundert." In Die Ritterorden als Träger der Herrschaft: Territorien, Grundbesitz und Kirche, herausgegeben von Jürgen Sarnowsky und Roman Czaja, I I 5- I 26. Ordines Militares. Colloquia Torunensia Historica XIV. Toruń: Wydawnictwo Uniwersytetu Mikołaja Kopernika, 2007.

Kreem, Juhan. "Die Lübecker in der Kommunikation des Deutschen Ordens im 16. Jahrhundert." In "Hansisch" oder "nicht-hansisch". Das Beispiel der kleinen Städte und Livlands in der Hanse, herausgegeben von Juhan Kreem und Jürgen Sarnowsky, 97- I I o. Hansische Studien 27. Wismar: Callidus, 2019.

Kreem, Juhan. "Netzwerke um Jasper von Munster. Der Deutsche Orden während der livländischen Koadjutorfehde im Jahre I 556." Ordines Militares Colloquia Torunensia Historica. Yearbook for the Study of the Military Orders 19 (2014): 73-86.

Kreem, Juhan. "Seasonality of Transport Network in the Eastern Baltic." In Towns and Comunication. Vol. 2. Communication between Towns, herausgegeben von Hubert Houben und Kristjan Toomaspoeg, 259-269. Saggi e Testi / Università Degli Studi Del Salento, Dipartimento Dei Beni Delle Arti e Della Storia 45. Galatina: Congedo, 20 II.

Kreem, Juhan. "The Archives of the Teutonic Order in Livonia: Past and Present." In Entre Deus e o Rei. O Mundo Das Ordens Militares, herausgegeben von Isabel Cristina Ferreira Fernandes, 57-65. Ordes militares 8. Palmela: Município de Palmela. Gabinete de Estudos sobre a Ordem de Santiago, 2018.

Lange, Thomas. Zwischen Reformation und Untergang Alt-Livlands. Der Rigaer Erzbischof Wilhelm von Brandenburg im Beziehungsgeflecht der livländischen Konföderation und ibrer Nachbarländer. Tlbd. I-2. Hamburger Beiträge zur Geschichte des östlichen Europa 2 I. Hamburg: Kovač, 2014.

Lange, Thomas. "Zwischen Unterwerfung und Konfrontation. Die Reformation in Riga im Spannungsfeld zwischen der Stadt und ihren Herren." In Preußen und Livland im Zeichen der Reformation, herausgegeben von Arno Mentzel-Reuters und Klaus 
Neitmann, 2 I I-240. Tagungsberichte der Historischen Kommission für ost- und westpreußische Landesforschung 28. Osnabrück: Fibre, 20 I 4.

Lückerath, Carl A. Paul von Rusdorf, Hochmeister des Deutschen Ordens 1422-I44I. Quellen und Studien zur Geschichte des Deutschen Ordens i 5. Bonn-Bad Godesberg: Verlag Wissenschaftliches Archiv, 1969.

Maasing, Madis. "Infidel Turks and Schismatic Russians in Late Medieval Livonia." In Fear and Loathing in the North, herausgegeben von Cordelia Heß und Jonathan Adams, 347-388. Berlin-München-Boston: de Gruyter, 2015.

Maasing, Madis. "Livland und die Reichstage (1520-1555)." In Livland - eine Region am Ende der Welt? Forschungen zum Verhältnis zwischen Zentrum und Peripherie im späten Mittelalter / Livonia - a Region at the End of the World? Studies on the Relations between Centre and Periphery in the Later Middle Ages, herausgegeben von Anti Selart und Matthias Thumser, 283-3 I 2. Quellen und Studien zur baltischen Geschichte 27. Köln-Weimar-Wien: Böhlau, 2017.

Maasing, Madis. "Livonia and depictions of Russians at Imperial Assemblies before the Livonian War”. Studia Slavica et Balcanica Petropolitana [im Druck].

Maasing, Madis. The Role of the Bishops in the Livonian Political System (in the First Half of the I 6 th Century). Dissertationes Historiae Universitatis Tartuensis 37. Tartu: Tartu Ülikooli kirjastus, 2016.

Maasing, Madis, und Dmitry Weber. "Die Gerüchte über den Tod des Erzbischofs Wilhelm von Riga im Sommer I 556.” Acta Historica Tallinnensia 25 (2019): 3- I 8.

Mäesalu, Mihkel. "Die Steuerforderungen des Heiligen Römischen Reiches an die Kirchenprovinz Riga im I 5. Jahrhundert." In Livland - eine Region am Ende der Welt? Forschungen zum Verhältnis zwischen Zentrum und Peripherie im späten Mittelalter / Livonia - a Region at the End of the World? Studies on the Relations between Centre and Periphery in the Later Middle Ages, herausgegeben von Anti Selart und Matthias Thumser, 259-282. Köln-Weimar-Wien: Böhlau, 2017.

Mäesalu, Mihkel. Liivimaa ja Püha Rooma keisririik IIg9-1486. Dissertationes Historiae Universitatis Tartuensis 42. Tartu: Tartu Ülikool, 2017.

Mahling, Madlena. "Raum und Zeit im Briefverkehr der livländischen Hansestädte mit Lübeck ( $1450-$ I 500)." In Livland - eine Region am Ende der Welt? Forschungen zum Verhältnis zwischen Zentrum und Peripherie im späten Mittelalter / Livonia - a Region at the End of the World? Studies on the Relations between Centre and Periphery in the Later Middle Ages, herausgegeben von Anti Selart und Matthias Thumser, 9 I-I 40. Quellen und Studien zur baltischen Geschichte 27. Köln-Weimar-Wien: Böhlau, 2017.

Mettig, Constantin. Geschichte der Stadt Riga. Riga: Jonck \& Poliewski, I 897.

The Military Orders and the Reformation: Choices, State Building, and the Weight of Tradition. Herausgegeben von Johannes A. Mol, Klaus Militzer, und Helen J. Nicholson. Bijdragen Tot de Geschiedenis van de Ridderlijke Duitsche Orde, Balije van Utrecht. Hilversum: Verloren / Utrecht: Ridderlijke Duitsche Orde Balije, 2006. 
Militzer, Klaus. “Bozen, Koblenz, Österreich und Elsass. Die Entstehung der hochmeisterlichen Kammerballeien des Deutschen Ordens." In Ders. Zentrale und Region: gesammelte Beiträge zur Geschichte des Deutschen Ordens in Preussen, Livland und im Deutschen Reich aus den Jahren Ig68 bis 2008, 26-44. Quellen und Studien zur Geschichte des Deutschen Ordens 75. Weimar: VDG, 2015.

Militzer, Klaus. Die Entstehung der Deutschordensballeien im Deutschen Reich. Quellen und Studien zur Geschichte des Deutschen Ordens, Bd. I6. Marburg: Elwert, I 98 I, 2., überarbeitete und erweiterte Auflage.

Militzer, Klaus. "Unterschiede in der Herrschaftsauffassung und Herrschaft und Verwaltung in den Zweigen des Deutschen Ordens." In Herrschaft, Netzwerke, Brüder des Deutschen Ordens in Mittelalter und Neuzeit. Vorträge der Tagung der Internationalen Historischen Kommission zur Erforschung des Deutschen Ordens in Marburg 2010, herausgegeben von Klaus Militzer, I-23. Quellen und Studien zur Geschichte des Deutschen Ordens 72. Weimar: VDG, 2012.

Misāns, Ilgvars. "Wolter von Plettenberg und der livländische Landtag." In Wolter von Plettenberg und das mittelalterliche Livland, herausgegeben von Norbert Angermann und Ilgvars Misāns, 55-7 I. Lüneburg: Verlag Nordostdeutsches Kulturwerk, 200 I.

Mol, Johannes A. "Traitor to Livonia? The Teutonic Orders' land marshal Jasper von Munster and his actions at the outset of the Livonian crisis, I $554-$ I 556 ." Ordines Militares Colloquia Torunensia Historica. Yearbook for the Study of the Military Orders 19 (2014): 205-240.

Müller, Ulrich. "Erzbischof Wilhelm von Riga und die Reformation in Livland I 535 - I 563." In Preußen und Livland im Zeichen der Reformation, herausgegeben von Arno Mentzel-Reuters und Klaus Neitmann, 24I-343. Tagungsberichte der Historischen Kommission für ost- und westpreussische Landesforschung 28. Osnabrück: Fibre, 20 I 4.

Murawski, Klaus-Eberhard. Zwischen Tannenberg und Thorn. Die Geschichte des Deutschen Ordens unter dem Hochmeister Konrad von Erlichshausen 144I-I449. Göttinger Bausteine zur Geschichtswissenschaft Io/ I I. Göttingen: Musterschmidt, I 953.

Neitmann, Klaus. "Rat und Ratsgebietiger Wolters von Plettenberg. Beobachtungen zum Regierungs- und Verwaltungsstil des Ordensmeisters." In Wolter von Plettenberg und das mittelalterliche Livland, herausgegeben von Norbert Angermann und Ilgvars Misāns, 85-I I I. Lüneburg: Verlag Nordostdeutsches Kulturwerk, 200 I.

Neitmann, Klaus. "Um die Einheit Livlands. Der Griff des Ordensmeisters Bernd von Borch nach dem Erzstift Riga um I 480." In Deutsche im Nordosten Europas, herausgegeben von Hans Rothe, I09-137. Studien zum Deutschtum in Osten 22. Köln-Wien: Böhlau, I 99 I.

Neitmann, Sonja. Von der Grafschaft Mark nach Livland: Ritterbrüder aus Westfalen im livländischen Deutschen Orden. Veröffentlichungen aus den Archiven Preussischer Kulturbesitz 3. Köln: Böhlau, I 993.

Piirimäe, Pärtel. "Staatenbund oder Ständestaat? Der livländische Landtag im Zeitalter Wolters von Plettenberg." Forschungen zur baltischen Geschichte 8 (20 I 3): 40-80. 
Quednau, Hans. Livland im politischen Wollen Herzog Albrechts von Preußen: ein Beitrag zur Geschichte des Herzogtums Preussen und des preussisch-livländischen Verbältnisses I525-I540. Deutschland und der Osten. Quellen und Forschungen zur Geschichte ihrer Beziehungen I 2. Leipzig: Hirzel, I939.

Raudkivi, Priit. Der livländische Landtag. Zur Entstehung einer mittelalterlichen Institution. Übersetzt von Hiltrud Kinnunen. Schriften der Baltischen Historischen Kommission 2 I. Berlin: Lit Verlag, 2018.

Der Reichstag 1486-I613: Kommunikation - Wahrnehmung - Öffentlichkeiten. Herausgegeben von Maximilian Lanzinner und Arno Strohmeyer. Schriftenreihe der Historischen Kommission bei der Bayerischen Akademie der Wissenschaften 73. Göttingen: Vandenhoeck \& Ruprecht, 2006.

Ritterbrüder im livländischen Zweig des Deutschen Ordens. Herausgegeben von Lutz Fenske und Klaus Militzer. Quellen und Studien zur baltischen Geschichte I 2. Köln-Weimar-Wien: Böhlau, I 993.

Die Ritterorden in Umbruchs- und Krisenzeiten. Herausgegeben von Roman Czaja und Jürgen Sarnowsky. Ordines Militares. Colloquia Torunensia Historica XVI. Toruń: Wydawnictwo Naukowe Uniwersytetu Mikołaja Kopernika, 20 I I.

Schaal, Katharina. Das Deutschordenshaus Marburg in der Reformationszeit. Der Säkularisationsversuch und die Inventare von 1543 . Untersuchungen und Materialien zur Verfassungs- und Landesgeschichte i 5 . Marburg: Elwert, 1996.

Schiemann, Theodor. "Landleben in Kurland im i 6. Jahrhundert. " In Characterköpfe und Sittenbilder aus der baltischen Geschichte des sechszehnten Jahrbunderts, I 27-I 5 I. Mitau: E. Behre, I 877.

Schulze, Winfried. Reich und Türkengefahr im späten I6. Jabrhundert. Studien zu den politischen und gesellschaftlichen Auswirkungen einer äußeren Bedrohung. Bd. I. München: Beck, I 978.

Schwarz, Jörg. "Zwischen Kaiser und Papst. Der Rigaer Erzbistumsstreit I 480-1 483." Zeitschrift für historische Forschung 34 (2007): 373-402.

Selart, Anti. "Political Rhetoric and the Edges of Christianity: Livonia and Its Evil Enemies in the Fifteenth Century." In The Edges of the Medieval World, herausgegeben von Juhan Kreem und Gerhard Jaritz, 55-69. CEU Medievalia i I. Budapest: Central European University, 2009.

Selart, Anti. "Иван Грозный, Кайзер Аивонский? К истории возникновения идеи о российского вассацьного государства в Аивонии”, Studia Slavica et Balcanica Petropolitana 2 (2013): I 80-197.

Seraphim, August. "Zur Geschichte und Kritik der angeblichen Statuten des Hochmeisters Werner von Orseln.” Forschungen zur brandenburgischen und preußischen Geschichte 28 (I 9 I 5): I -82.

Sternheim, Jaron. "Politische Akteure zwischen päpstlicher Kurie und Livland. Das Beispiel Stephan Grube, Erzbischof von Riga ( $1480-1483$ )." In Livland - eine Region am Ende der Welt? Forschungen zum Verhältnis zwischen Zentrum und Peripherie im späten Mittelalter / Livonia - a Region at the End of the World? Studies on the Relations 
between Centre and Periphery in the Later Middle Ages, herausgegeben von Anti Selart und Matthias Thumser, 237-258. Köln-Weimar-Wien: Böhlau, 2017.

Ten Haaf, Rudolf. Deutschordensstaat und Deutschordensballeien. Untersuchungen über Leistung und Sonderung der Deutschordensprovinzen in Deutschland vom I3. bis zum I6. Jahrbundert. Göttinger Bausteine zur Geschichtswissenschaft 5. Göttingen: Musterschmidt, 1954, 2. Auflage.

Toomaspoeg, Kristjan. "Der Verlust der Besitzungen des Deutschen Ordens in Italien am Ende des I 5. und zu Beginn des 16. Jahrhunderts." Ordines Militares Colloquia Torunensia Historica. Yearbook for the Study of the Military Orders 2 I (2016): I 29 - I 54. Wimmer, Elke. "Livland - ein Problem der habsburgisch-russischen Beziehungen in der Zeit Maximilians I.?" In Deutschland - Livland - Russland: ihre Beziehungen vom I5. bis zum 17. Jabrbundert. Beiträge aus dem Historischen Seminar der Universität Hamburg Deutschland, herausgegeben von Norbert Angermann, 53-I I ०. Lüneburg: Nordostdeutsches Kulturwerk, 1988. 